\title{
The Opportunity Costs of \\ Conservation with Deterministic and \\ Probabilistic Degradation \\ Externalities
}

Esther Blanco, Maria Claudia Lopez, James M. Walker

Working Papers in Economics and Statistics

2012-25

Updated version. Accepted Manuscript

https://doi.org/10.1007/s10640-014-9868-7 


\section{University of Innsbruck \\ Working Papers in Economics and Statistics}

The series is jointly edited and published by

- Department of Banking and Finance

- Department of Economics

- Department of Public Finance

- Department of Statistics

Contact address of the editor:

Research platform "Empirical and Experimental Economics" University of Innsbruck

Universitaetsstrasse 15

A-6020 Innsbruck

Austria

Tel: $\quad+435125077171$

Fax: $\quad+435125072970$

E-mail: eeecon@uibk.ac.at

The most recent version of all working papers can be downloaded at http://eeecon.uibk.ac.at/wopec/

For a list of recent papers see the backpages of this paper. 


\title{
The opportunity costs of conservation with deterministic and
}

\section{probabilistic degradation externalities}

\author{
Esther Blanco ${ }^{\mathrm{a}, \mathrm{d}, \uparrow}$ \\ Maria-Claudia Lopez ${ }^{\text {b,d }}$ \\ James M. Walker ${ }^{\mathrm{c}, \mathrm{d}}$ \\ ${ }^{a}$ Department of Public Finance, University of Innsbruck, Austria. Universitaetsstrasse 15, 6020, \\ Innsbruck, Austria.e-mail: esther.blanco@uibk.ac.at. \\ ${ }^{b}$ Department of Community Sustainability, Michigan State University, USA. 326 Natural \\ Resources Building, 480 Wilson Road. Michigan State University. East Lansing, MI 48824. e- \\ mail:mlopez@msu.edu \\ ${ }^{c}$ Department of Economics, Indiana University, USA. Wylie Hall 105. Indiana University. \\ Bloomington, IN 47405.e-mail: walkerj@indiana.edu. \\ ${ }^{d}$ The Vincent and Elinor Ostrom Workshop in Political Theory and Policy Analysis, Indiana \\ University, USA. \\ $\dagger$ Corresponding author: Telephone: $+43(0) 5125077160$. Fax: $+43(0) 5125072788$. e-mail: \\ esther.blanco@uibk.ac.at
}

Acknowledgments: Financial support was provided by the University of Innsbruck. The authors also acknowledge the support of the National Science Foundation (grant number SES-0849551). We are grateful to Paula Andrea Zuluaga, Adriana Beltran and Tobias Haller for their outstanding assistance and to Glenn Dutcher, Brock Stoddard, and participants in the 5th World Congress of Environmental and Natural Resource Economists and in the Experimental Reading Group of the University of Innsbruck for comments on previous versions of this paper. 


\title{
The opportunity costs of conservation with deterministic and
}

\section{probabilistic degradation externalities}

\begin{abstract}
This experimental study examines variations in the opportunity cost of conservation in two linear appropriation games that include symmetric and asymmetric subject payoffs. In the first game, appropriation leads to deterministic degradation in the value of a shared resource. In the second game, appropriation leads to both deterministic and probabilistic degradation, introducing endogenous uncertainty in the value of the opportunity cost of conserving the shared resource. The results show that subjects systematically decrease appropriation the lower the opportunity cost of conservation, and the addition of probabilistic degradation leads to further decreases in group appropriation. As conjectured, the response of individual subjects to the addition of probabilistic degradation is conditional on their expected marginal net benefits to appropriate, which depend in turn on their first order beliefs of others' appropriation. The overall decreases in appropriation due to probabilistic degradation, however, are not large enough to offset decreases in expected efficiency due to expected losses in the value of the shared resource.
\end{abstract}

Keywords: asymmetry $\cdot$ social dilemma $\cdot$ cooperation $\cdot$ laboratory experiment

JEL Classification: $D 7 \cdot H 4 \cdot C 90$

This paper has not been submitted elsewhere in identical or similar form, nor will it be during the first three months after its submission to the Publisher. 


\section{The opportunity costs of conservation with deterministic and}

\section{probabilistic degradation externalities}

\section{Introduction}

This study is designed to complement the earlier literature on common-pool resources (CPRs) and public goods settings by examining the mediating effect of deterministic and probabilistic degradation externalities on the responses to variations in marginal incentives to appropriate. The experimental design examines variations in the opportunity cost of conservation (foregone private earnings from appropriation) in two linear appropriation games that include symmetric and asymmetric subject payoffs. In the first game, appropriation leads to deterministic degradation in the value of a shared resource. In the second game, appropriation leads to both deterministic and probabilistic degradation, introducing by design endogenous uncertainty in the value of the opportunity cost of conserving the shared resource.

The design of the study is motivated by four main observations. First, conservation of natural resources generates a public good in the form of ecosystem services. Substantial research efforts are currently being undertaken to quantify the economic relevance of such ecosystem services (see, for example, Costanza et al. 1997) ${ }^{1}$ and the loss of ecosystem services associated to climate change (e.g. Schröter et al. 2005). Appropriation from natural resources that provide these ecosystem services generates negative externalities, referred to here as degradation externalities. For example, in the context of climate change, degradation externalities associated with deforestation can be understood as the loss of carbon sequestration that the forest would have provided. The linear appropriation games used in this study capture the essence of such degradation externalities. In these decision environments, a group of subjects appropriate from a 
resource (e.g. forest), gaining private value from resource units appropriated (e.g. timber), as well as group value (representing the ecosystem services) from units left in the shared resource (e.g. carbon sequestration). This decision environment relates to earlier experimental studies that address settings in which subjects' decisions can be viewed in the context of negative externalities, or preventing a public bad (Andreoni 1995; Sonnemans et al. 1998; Dufwenberg et al. 2011; Cox et al. 2013). The goal of this study is not to address the role of positive or negative frames in such games. Instead, as discussed below, the appropriation games examined here provide a simple and conceptually appropriate setting for investigating behavior as related to degradation of ecosystem services.

Second, appropriation from natural resources can (endogenously) lead to probabilistic losses of ecosystem services beyond the day-to-day deterministic degradation associated with appropriation. A particularly relevant example is the probabilistic catastrophic outcomes associated with climate change. For example, deforestation induces deterministic damages over ecosystem services worldwide, as well as increasing the probability that catastrophic outcomes associated with climate disruptions emerge. Other contexts where such probabilistic losses are relevant are in biodiversity loss and desertification associated with land conversion. The greater the primary habitat that is lost, the greater is the probability that major biodiversity losses or desertification process takes place. Motivated by issues of climate change, several previous experimental studies have examined the relevance of exogenous probabilities of group losses (e.g. Milinski et al 2008; Barrett and Dannenberg, 2012). Other experimental literature, more relevant to this study, examines endogenous probabilistic losses. Walker and Gardner (1992) introduced an endogenous probability that a repeated play CPR game would end, where the probability of ending the game increased in total group appropriation. Dickinson (1998) and 
Gangadharan and Nemes (2009) address the relevance of an endogenous probability of a linear public good being provided. In the "incentive treatment" in Dickinson (1998), investments in the group account increase the probability of provision as well as the size of the group good, although even with full cooperation provision is not guaranteed. In Gangadharan and Nemes (2009), treatment 7 most closely parallels our study. In this treatment, subjects face both exogenous and endogenous uncertainty over the probability of receiving a return from investments in the group good. Beyond important differences in the game forms across the studies, there are two additional important differences in our study relative to these studies. First, we focus on contrasting within-subjects behavior in settings with probabilistic degradation to settings without. Second, our comparisons are made in settings in which private appropriation benefits are varied.

The third observation motivating the design of our study is that in many field settings conservation decisions are made in contexts of limited information as to the actions of other agents. The limitation of information reduces the relevance of group dynamics as a driving force of users' appropriation decisions. ${ }^{2}$ For example, despite recent efforts to quantify the extent of forest degradation and deforestation, land conversion decisions from forest to agriculture or pastures by small scale farmers or herders is often undertaken without information on land use change by others. Similarly, at the international level, programs designed to encourage biodiversity protection face difficulties in obtaining and sharing information across regions on the existence and state of different species. From an experimental design perspective, this suggests the need to complement the previous literature by examining the influence of variations in the marginal incentives to appropriate in decision settings that move away from the context of repeated decisions that include feedback about group appropriation. The menu-design 
incorporated here allows for contrasting own-subject decisions across parameter manipulations, while removing opportunities for signaling cooperative intentions, as well as monitoring others' decisions across decision rounds.

Finally, prior research has argued that collective action and crafting institutions to conserve natural resources are often exacerbated by asymmetries in incentives for appropriation (e.g. Ostrom, 2009). Thus, we explore the responses of subjects to deterministic and probabilistic degradation of a shared resource under varying values of the marginal incentives to appropriate in both symmetric and asymmetric settings.

\section{The decision settings}

We investigate behavior in what we refer to as the "Deterministic Degradation" game (hereafter DD) and the "Deterministic and Probabilistic Degradation" game (hereafter DPD). In addition, as in similar studies, we incorporate incentivized belief elicitation for other subjects' appropriation for each of the decision settings (e.g. Offerman et al. 1996; Croson 2007). The menu design used in our study is similar to that used in several other studies such as Brandts and Schram (2001), who advocate the use of this method as a mechanism to create a rich data set related to individual decision making. In this manner, subjects in this study make decisions across eight decision settings that vary deterministically and probabilistically the marginal incentives to appropriate. The structure of each game, experimental parameters, and marginal incentives are discussed below. 


\subsection{The Appropriation game with deterministic degradation}

In the DD game, groups of $n$ agents face allocation decisions between a "Group Fund" and an "Individual Fund." Each group begins with a Group Fund endowment of $t$ tokens, and each agent begins with zero tokens allocated to their Individual Fund. Agents simultaneously and privately decide how many tokens to move from the Group Fund to their Individual Fund. ${ }^{3}$ Each token in an agent's Individual Fund has a marginal private benefit of $P B$ ECUs (Experimental Currency Units) for the agent, and each token remaining in the Group Fund has a value of $g$ ECUs for the group. Parameter $P B$ is therefore the marginal private value of appropriation, which is manipulated to generate variations in the opportunity cost of conservation. Each token left in the Group Fund has a value of $g / n$ ECUs for each group member. Agents have an equal capacity to withdraw up to $e$ tokens from the Group Fund, parameterized so that full extraction by all subjects results in a Group Fund of zero tokens. Thus, the Group Fund can be viewed as a public good that when conserved yields symmetric benefits of $g / n$ to each group member and appropriation leads to a loss in the total value of the public good.

In summary, letting $z_{i}$ denote the amount appropriated from the Group Fund by agent $i$, the payoff to agent $i$ in the DD game can be represented as:

$$
\pi_{i}^{D D}=P B \cdot z_{i}+\frac{g}{n} t-\frac{g}{n} \sum_{i=1}^{n} z_{i} \quad z_{i} \in(0, e)
$$

where $\frac{g}{n} \sum_{i=1}^{n} z_{i}$ is the deterministic loss in the value of the Group Fund caused by the group appropriation. Thus, in the DD game, the marginal net benefit from appropriation is:

$$
M N B_{i}^{D D}=P B_{i}-g / n
$$


The games are parameterized such that $g>P B$ and $(g / n)<P B$ to create a social dilemma. By imposing the condition that $g / n<P B$ for the parameters investigated, the net gain from appropriation is always positive. Thus, assuming agents make decisions based on own income maximization, each agent has a dominant strategy to withdraw $e$ tokens from the Group Fund. The game represents a social dilemma, however, in that the optimum is for all agents to withdraw zero tokens from the Group Fund.

Clearly, the DD game as described above abstracts from the complex combinations of production externalities (as described by Gordon, 1954, and Hardin, 1968), degradation externalities, and path dependencies prevalent in the use of natural resources in the field. The focus of this study is to isolate to what degree decision makers respond to the tension between private benefits of appropriation and the public good externalities produced in maintaining the resource. A primary rationale for using this game form is its simplicity. This simplicity allows for manipulations in marginal incentives and heterogeneity in incentives that are transparent to subjects. Most importantly, the simplicity of DD game also makes it a good vehicle for the addition of probabilistic degradation.

\subsection{The Appropriation game with deterministic and probabilistic degradation}

The DPD game adds an additional component of probabilistic degradation to the DD game. The instructions of the DPD games included the statement that "for each token removed from the initial Group Fund by a member of your four person group there is a $1 \%$ chance that the value of the final Group Fund is reduced by one-half." Thus, probabilistic degradation is implemented as a hazard rate that depends on the aggregate number of tokens moved from the Group Fund. Degradation is a loss, $L$, of $50 \%$ of the total value of the remaining Group Fund after all decisions are final. The endogenous probability of this loss (degradation) occurring is $P=$ 
$\left(p \sum_{i=1}^{n} z_{i}\right)$, where $p=1 \%$. Thus, each token appropriated from the Group Fund by an agent increases by $1 \%$ the probability that the value of the final Group Fund is reduced by $50 \%{ }^{4}$ The resulting payoff to agent $i$ in the DPD game is:

$$
\pi_{i}^{D P D}=P B z_{i}+\frac{g}{n} t-\frac{g}{n} \sum_{i=1}^{n} z_{i}-\left(\frac{g}{n}\right)\left[\mathrm{L}\left(p \sum_{i=1}^{n} z_{i}\right)\left(t-\sum_{i=1}^{n} z_{i}\right)\right] \quad z_{i} \in(0, e)
$$

where the last term on the right-hand side of equation 3 is the additional probabilistic loss from appropriation. Introducing the probability of degradation changes an individual's marginal net benefit from appropriation relative to the DD game:

$$
M N B_{i}^{D P D}=P B_{i}-\frac{g}{n}-\frac{g}{n} L p\left(t-2 \sum_{i=1}^{n} z_{i}\right)
$$

Thus, in comparison to equation 2, there is an additional third component. Importantly, as discussed in more detail in section 2.4, the sign of this component depends on the relation between the initial value of the Group Fund, $t$, and aggregate appropriation, $\sum_{i=1}^{n} z_{i}$. Thus, introducing the additional component of probabilistic degradation causes the magnitude of marginal incentives to appropriate to be dependent upon aggregate group appropriation. In addition, as discussed below in section 2.4, for the parameterization with the lowest value of $P B$, the marginal incentives to appropriate in the DPD game are so small that there are two equilibria in pure strategies, one with full appropriation and a second with zero appropriation.

\subsection{Game parameters}

All decision settings included groups of four, with an initial endowment of 100 tokens in the Group Fund from which each subject could move up to 25 tokens to their Individual Funds. Tokens in the Group Fund had a marginal value of 2 ECUs for all decision settings, shared equally among group members. As shown in Table 1, all parameter variations arise from varying the value of $P B$, the marginal private benefit of tokens in an agent's Individual Fund. Relative to 
a medium value of $P B=1$, we examine cases where the value of $P B$ is increased $(P B=1.4)$, and lowered $(P B=0.6)$ both in the DD and DPD games.

(Table 1 about here)

In games with asymmetric incentives, two group members receive a high value of $P B$ (1.4) and two receive a low value (0.6). This allows for comparisons between symmetric and asymmetric decision settings for subjects with the same value of $P B$. In addition, the high and low values are chosen so that the average value of $P B$ for the asymmetric groups (average $P B$ of 1 ) is the same as for the symmetric medium value of $P B=1$. This enables us to compare decision settings based on the average marginal incentives in a group. Relative to previous studies, these aspects of the design allows us to more systematically compare appropriation decisions in symmetric and asymmetric settings. In particular, previous public good experiments focus on only a subset of these comparisons (Bagnoli and McKee 1991; Chan et al. 1999; Fisher et al. 1995; Tan 2008; Noussair and Tan 2011; Nikiforakis et al. 2012; Reuben and Riedl 2013; Fischbacher et al. forthcoming). ${ }^{5}$

\subsection{Marginal net benefits from appropriation and efficiency}

Given the parameter values shown in Table 1, in the medium $P B$ value for the DD game, the marginal net gain from appropriation for each subject is 0.5 ECUs (column 4 in Table 1). That is, regardless of the appropriation decisions of other group members, for each individual, extracting one token implies gaining 1 ECU privately and foregoing 0.5 ECUs from maintaining the Group Fund. As described above, since the marginal net gain from appropriation is positive, the Nash equilibrium based on all subjects maximizing their own monetary gains is for all players to appropriate up to their individual capacity. Using the same logic for the other parameters 
investigated in the DD game, $P B=1.4$ or 0.6 , the equilibrium prediction is not changed despite the change in the marginal net gain from appropriation, which are 0.9 and 0.1 , respectively.

For the DPD game, net marginal incentives are more complex (column 4 in Table 1). In comparison to the DD game, for levels of group appropriation that are sufficiently low (more precisely for $2 \sum_{i=1}^{n} z_{i}<t$ ), the marginal incentive to appropriate in the DPD game is lower than in the DD game. For appropriation levels that are sufficiently high $\left(2 \sum_{i=1}^{n} z_{i}>t\right)$, the marginal incentive to appropriate in the DPD game is higher than in the DD game. For an initial group fund with 100 tokens studied here, aggregate group appropriation equal to 50 tokens $(t / 2)$ becomes a switching-point. In summary,

$$
\text { for all values of } P B ; \quad\left\{\begin{array}{ll}
\text { iff } \sum_{i=1}^{n} z_{i}<50 & M N B_{i}^{D P D}<M N B_{i}^{D D} \\
\text { iff } \sum_{i=1}^{n} z_{i}>50 & M N B_{i}^{D P D}>M N B_{i}^{D D}
\end{array}\right\}
$$

Equation 4 also implies that if the component $\frac{g}{n} L p\left(t-2 \sum_{i=1}^{n} z_{i}\right)$ is negative and large (in absolute value) relative to the value of $P B$, the marginal incentive to appropriate in the DPD game, $M N B_{i}^{D P D}$, can be negative. This only holds for the treatment conditions with a value of $P B=0.6$ in the DPD games (DPD-LowPB and low $P B$ subjects in DPD-Asym). The implication is that for these treatment conditions, the dependence of marginal incentives on the level of group appropriation leads to the existence of two Nash equilibria in pure strategies:

$$
\text { iff } P B=0.6 ; \quad\left\{\begin{array}{ll}
\text { and } \sum_{i=1}^{n} z_{i}<30 & M N B_{i}^{D P D}<0 \\
\text { and } \sum_{i=1}^{n} z_{i}>30 & M N B_{i}^{D P D}>0
\end{array}\right\}
$$

Thus, under a $P B=0.6$ in DPD games there is no incentive to appropriate for levels of group appropriation smaller than 30 tokens, and it follows that appropriation of zero tokens becomes a Nash equilibrium. For group appropriation levels above 30 tokens, the Nash equilibrium is to appropriate at maximum capacity, as in the DD games. For decision settings where $P B=1$ and $P B=1.4$, it holds that $M N B_{i}^{D P D}>0$ at all levels of appropriation, and thus the Nash equilibrium 
is appropriating at maximum capacity, as in the DD games. Regardless of the decision setting, the social optimum is zero appropriation.

In addition to net benefits from appropriation, it is relevant to understand the implications of changes in the opportunity cost of conservation $(P B)$ and of introducing probabilistic degradation, on economic efficiency $(\varepsilon)$. For this purpose, in the DD game situations, group efficiency is defined in each decision situation $j$ as:

$$
\varepsilon_{j}^{D D}=\left(P_{j}-\min P_{j}\right) /\left(\max P_{j}-\min P_{j}\right)
$$

where $P_{j}$ is the group payoff in decision situation $j, \min P_{j}$ is the minimum possible payoff in $j$, which corresponds to the payoffs at Nash Equilibrium that vary between the different decision situations, and $\max P_{j}$ is the maximum possible payoff in $j$, the social optimum, that is constant across all decision situations. Notice that for identical appropriation levels, efficiency varies across decision situations through $P_{j}$, as well as through the minimum possible payoff, $\min P_{j}$, defined by the Nash Equilibrium.

For the DPD games, one must account for the potential probabilistic loss of earnings resulting from aggregate group appropriation. Thus, in the DPD game, efficiency is calculated as:

$$
\varepsilon_{j}^{D P D}=\left(E\left[P_{j}\right]-\min P_{j}\right) /\left(\max P_{j}-\min P_{j}\right)
$$

where $E\left[P_{j}\right]$ is the expected payoff based on group appropriation in decision situation $j$. In all DPD games the $\min P_{j}$ is the payoff in the Nash equilibrium of full appropriation; ${ }^{6}$ and $\max P_{j}$ is the payoff at the social optimum, which is constant across all decision settings. Note, at the social optimum the probability of degradation is zero, and if subjects appropriate to full capacity there is a $100 \%$ probability of degradation. In this latter case, however, because the Group Fund is fully exploited, the probabilistic degradation is irrelevant. Finally, notice that for the same 
level of appropriation in DPD game, expected efficiency will be lower than in the DD game due to the probabilistic loss associated with appropriation.

\section{Behavioral conjectures}

Numerous experimental studies conducted over the past several decades have demonstrated that individuals' decisions in a variety of social dilemma situations reflect complex and diverse motivations beyond simple self-income maximization (see research summarized in Camerer 2003; Camerer and Fehr 2006; Ostrom and Walker 2003). Extensive experimental research, replicated across multiple cultures, has led to the development of a wide variety of models designed to reflect such motivations. For example, based on social norms such as conditional cooperation or social preferences (e.g. Fehr and Schmidt 1999; Fischbacher et al. 2001; Cox et al. 2008), individuals may cooperate even in one-shot settings. Thus, it is important to unveil regularities in subjects' responses to changes in marginal incentives that are outside of the equilibria predicted by standard own-income maximization. In this vein, conjectures 1 and 2 below summarize behavioral hypotheses as related to the treatments examined in this study. Conjecture 1 focus on responses to variations in marginal incentives to appropriate (the opportunity costs of conservation) within DD and DPD games, while conjecture 2 focuses on across game comparisons (DPD vs. DD).

Conjecture 1: Increasing the private benefit of appropriation will lead to greater appropriation from the Group Fund.

Thus, irrespective of the nature of the degradation imposed by appropriating from the resource, subjects will respond to the relative opportunity cost of conservation. More specifically, as related to the treatment conditions studied here: (a) within decision settings in which all subjects 
face the same marginal incentives, increasing the private benefit of appropriation leads to greater appropriation from the Group Fund; (b) appropriation by individuals in asymmetric settings with higher private benefits to appropriate will be greater than those of individuals with lower private benefits; and (c) appropriation in asymmetric and symmetric decision settings will be the same for individuals having the same marginal private benefits to appropriate.

Conjecture 2: If subjects' expectations of the appropriation levels of the group are sufficiently low, ceteris paribus, individual appropriation levels in DPD games will be lower than in DD games.

Conjecture 2 is based on the effect of changes in marginal incentives to appropriate for the DPD game as compared to the DD game. As shown in section 2.4, for the parameters considered here, sufficiently low expectations of aggregate group appropriation imply expected group appropriation of less than 50 tokens.

\subsection{Related literature}

The experimental literature investigating CPR settings has not systematically explored the implications of changes in marginal incentives to appropriate. However, numerous studies examining provision decisions in public good games have addressed variations in the value of the private fund (e.g., Isaac et al. 1994; Fisher et al. 1995; Falkinger et al. 2000; Brandts and Schram 2001). These studies, along with others varying the value of the group fund (see reviews in Ledyard 1995 and Chaudhuri 2011), have shown the MPCR, the ratio of marginal benefits from the public good relative to private benefit, to be instrumental in explaining variations in contributions across groups. This literature investigating the role of the MPCR has primarily been in the context of repeated game settings. 
Turning to behavioral responses to asymmetries in marginal benefits from appropriation, recent discussions found in Nikiforakis et al. (2012) and Reuben and Riedl (2013) provide an argument that asymmetries in private returns among group members may introduce normative conflicts in decision making. In particular, asymmetries induce at least two plausible rules for subjects to adopt that would yield different outcomes - namely, equal contributions and equal payoffs. In terms of findings from experimental studies, the results are somewhat mixed. Margreiter et al (2005) find that in CPR settings with asymmetric appropriation costs, average group appropriation is not statistically different from average appropriation in symmetric groups with intermediate costs. ${ }^{7}$ A similar result is found in the public goods study of Fisher et al. (1995). There are, however, several studies examining public goods environments that find a "poisoning of the well" effect whereby average group contributions for asymmetric groups are lower than in symmetric groups (Bagnoli and McKee 1991; Chan et al. 1999; Tan 2008; Fischbacher et al. forthcoming). Note, a fundamental difference between these earlier studies and the design presented here is that the one-shot nature of our study does not allow for the path dependent group dynamics that allow for reputation building in repeated decision settings. Thus, given the one-shot nature of our decision setting, void of communication and punishment mechanisms, results from previous studies are not directly comparable to our study. We conjecture that subjects will change appropriation levels based on changes in their own marginal incentives and subjects with higher values of $P B$ will appropriate more. Further, not only will subjects with higher incentives appropriate more than subjects with lower incentives and vice versa, but they will appropriate at a level equal to that observed in symmetric decision settings with the same marginal incentives. 
Of the limited previous evidence on endogenous probabilistic settings (Walker and Gardner, 1992; Dickinson, 1998; Gangadharan and Nemes 2009), Dickinson (1998) is most closely related to this study in the sense that he directly compares a treatment condition with endogenous probabilistic provision of a public good to a setting with certainty over the value of contributions to the public good. In his repeated game setting, Dickinson utilizes group contributions from the previous round to form subjects' expectations of current-round group contributions. His results support the conjecture that expectations of marginal per capita return have a positive and significant effect on contributions. The menu-design presented here combined with the incentivized belief elicitation allow us to explicitly address the relevance of expectations of marginal incentives. As discussed in section 2.4, in comparing DD and DPD games, the relative size of marginal incentives to appropriate switch at an expected group appropriation of 50 tokens. The presentation of results empirically addresses the relevance of the

threshold of 50 tokens as well as of the expected marginal net benefits to appropriate, $M N B_{i}^{\prime}$, on the response to probabilistic degradation.

\section{The experimental decision setting}

The experiment consisted of eight sessions conducted with a total of 128 university students. Each session included 8 to 20 subjects. At the start of each session, subjects were presented with a packet that included initial instructions (see Appendix A for an English translation of instructions), a consent form, and instructions for each of the decision settings with subjectspecific parameters. In addition, the initial instructions informed the subjects that each subject would make choices in each decision setting, and their compensation would be based on the outcome of one of the decision settings chosen randomly at the end of the experiment after all 
decisions were final. The decision setting chosen for compensation would be selected by publicly picking a card out of a shuffled deck of cards numbered from 1 to 8 . Groups of four were created based on subject numbers that were assigned randomly and anonymously at the beginning of the experiment. Cash earnings depended on each subject's decisions and the decisions of the other three participants in their group. All decisions and earnings were private information. Decision settings were described in ECUs with a conversion rate of US\$0.34 for each ECU. After receiving this information, subjects were asked to read and sign the consent form if they were willing to participate in the experiment.

After completing the initial instructions, the experimenters reviewed instructions for each decision setting. As discussed above, in all decision settings each group began with a Group Fund of 100 tokens and each token in the initial Group Fund was worth 2 ECUs. Each group member began with an Individual Fund containing zero tokens. Each person's decision task was to decide privately and independently whether to move up to a maximum of 25 tokens $(0,1,2,3, \ldots, 23,24$, or 25$)$ from the Group Fund to his/her own Individual Fund. Each token that a person moved from the Group Fund increased the value of his/her own Individual Fund by 1 ECU for the DD-MedPB decision setting. The additional DD decision settings were identical to the DD-MedPB situation except for the value of tokens moved to a group member's Individual Fund as described in Table 1, including DD-HighPB, DD-LowPB, and DD-Asym(pooled PB). In the DPD games, subjects received additional instructions that explained that for each token removed from the initial Group Fund by a four-person group, there was a $1 \%$ chance that the value of the final Group Fund would be reduced by one-half. The same variations in the value of tokens in the Individual Fund were applied in the DPD games, resulting in the 
corresponding DPD-HighPB, DPD-MedPB, DPD-LowPB, and DPD-Asym(pooled PB) decision settings (as shown in Table 1).

After the instructions were given for all decision settings, the experimenters displayed the parameters for all decision settings using a projector. Concurrently, decision sheets were distributed to subjects, who then completed two copies: one to hand back to the experimenter once all decisions were final and one to keep until the end of the session. As in Brandts and Schram (2001), it was the subjects' choice to determine the order in which he/she made decisions in the eight decision settings. Importantly, the decision for any situation could be revised as long as all decisions had not been finalized and handed back to the experimenter.

After all appropriation decisions were finalized, and before receiving any feedback information, subjects were informed of the forecasting task presented to them as "bonus questions." These would yield additional earnings to be added to their earnings from the first part of the session. In this bonus task, each subject was asked to report a forecast of the average perperson appropriation level for members of their group, for each of the eight decision settings. While making their forecasts, subjects had their copy of their decision-making sheet. Belief elicitation was incentivized following Croson (2007). If a subject's forecast of the per-person average number of tokens appropriated was equal to or not more than 1 token away from the actual average of the other group members, he/she earned an additional US\$4.5. If the forecast was more than 1 token away from the average, he/she earned US\$1.7 divided by the (absolute) distance between the forecast and the actual average. For the asymmetric decision setting, subjects forecasted the average per-person appropriation of high $P B$ and of low $P B$ subjects separately, which was then used to construct the composite per-person forecast of other group members. The composite value was constructed for Low- $P B$ (High- $P B$ ) subjects aggregating 
individual forecasts of two high (low) and one low (high) incentive subject and dividing by 3 . Only the forecast corresponding with the decision setting chosen for computing game earnings was used for the bonus payment. ${ }^{8}$

\section{Results}

The results provide general support for each of the two conjectures. In summary, higher values of $P B$ correspond to higher average appropriation levels, resulting in lower efficiency in use. This is true regardless of game type (DD or DPD) and regardless of whether incentives are symmetric or asymmetric. Further, as conjectured, subjects respond systematically to the addition of probabilistic degradation. On average, appropriation levels in the DPD game settings are significantly lower relative to the DD game settings. This effect is mediated by the size of the perceived MNB. That is, based on forecasts, subjects who expect the group appropriation to be above 50 tokens appropriate significantly more in DPD games relative to DD games. In particular, the expected marginal net benefits to appropriate, $M N B_{i}^{\prime}$, which in turn depends on the expectations on the sum of group appropriation, is a significant predictor of the response of subjects to the probabilistic environment.

Because the decision settings are one-shot and subjects did not receive feedback information until all decisions were final, the presentation of results is based primarily on individual decisions as opposed to group decisions. Figure 1, panels A and B, presents summary information related to average individual appropriation in the DD and in the DPD games, across decision settings that vary the value of $P B .{ }^{9}$ In addition, for each decision setting, Table 2 includes summary statistics related to average individual and group appropriation, frequency of maximum allowable and zero appropriation, efficiency, and forecasts of individual 
appropriation. ${ }^{10}$ For both DD and DPD games settings, Table 3 (panels A and B respectively) presents the results from paired t-tests on individual decisions across pairs of treatment conditions, where bold cells are the relevant comparisons for conjecture 1.

(Figures 1 and 2 and Tables 2, and 3 about here)

Consistent with conjecture 1, panel A in Figure 1 shows evidence in symmetric decision settings of a positive relationship between the level of appropriation and the value of $P B$. As shown in Table 3 panels A and B, these differences are all statistically significant in both DD and DPD games. Similarly, data presented in panel B in Figure 1 and Table 3 is consistent with conjecture 1 for asymmetric decision settings. In the asymmetric treatments subjects with high$P B$ values appropriate significantly more than subjects with low- $P B$ values. Furthermore, Figure 2 shows that for the same value of $P B$, appropriation by individuals in symmetric and asymmetric decision settings is very similar. More specifically, Table 3 shows, in support of conjecture 1, that differences in average appropriation are not significantly different for the pairwise comparisons of DD-HighPB vs. DD-Asym(PB=1.4) and DD-LowPB vs. Asym( $\mathrm{PB}=0.6)$, as well as for DPD-HighPB vs. DPD-Asym(PB=1.4) and DPD-LowPB vs. DPD-Asym(PB=0.6). ${ }^{11}$

(Tables 4, 5 and 6 about here)

Conjecture 2 focuses on comparisons of behavior between DD and DPD games. Figure 1 shows that, in support of conjecture 2, average appropriation in DPD decision settings is lower than in DD in all paired comparisons. Paired t-tests in Table 4 show that these differences are statistically significant in all cases except for subjects with a low- $P B$ in the asymmetric treatment, $\mathrm{Asym}(\mathrm{PB}=0.6)$. However, when pooling high $P B$ and low $P B$ subjects in the 
asymmetric treatment Asym(pooled PB), the difference between DD and DPD games is significant.

In further analysis related to conjecture 2, Table 5 presents a first approximation to exploring the potential for different responses across subjects to endogenous probabilistic degradation, based on subjects' first order beliefs and associated implications for marginal incentives. In this OLS analysis, subjects' change in appropriation between DD and DPD games serves as the dependent variable. Using subjects' forecasts of group appropriation across game settings, the estimates in Table 5 includes a dummy variable (DUM $>50$ ) that takes a positive value for subjects who expect the sum of aggregate appropriation in their group to be above the critical threshold of 50 tokens. Consistent with conjecture 2, this variable shows a positive and significant coefficient. ${ }^{12}$ An alternative analysis is to directly address the relevance of the expected marginal net benefits, $M N B_{i}^{\prime}$. The variable $M N B_{i}^{\prime}$ in the OLS analysis presented in Table 6 is based on equation 4, considering the subject's expected appropriation of the other three members in his/her group and his/her own appropriation. ${ }^{13}$ As conjectured, this variable has a significant positive coefficient in all symmetric decision settings. In the treatments with asymmetric private benefits, the appropriation by high- $P B$ subjects, $A s y m(P B=1.4)$, significantly increases in the size of $M N B_{i}^{\prime}$, but it does not significantly increase for low- $P B$ subjects, Asym( $P B=0.6)$ ( $p$-value 0.108). This suggests that the response to probabilistic degradation on subjects' appropriation decisions is more consistent in symmetric decision settings where all group members have the same private benefits from appropriation. The results for Asym(Pooled PB) are presented in Table 6 for completeness. The lack of a significant coefficient for $M N B_{i}^{\prime}$ in the pooled analysis relates to the variability in responses (substantially different for the intercepts) for the cases of $\mathrm{Asym}(\mathrm{PB}=0.6)$ and $\mathrm{Asym}(\mathrm{PB}=1.4) .{ }^{14}$ 
Finally, we turn to the question of economic efficiency. The reported differences in individual appropriations between decision settings results in clear differences in efficiencies (defined in equations 7 and 8). As shown in Table 2, efficiency levels range from a low of $10 \%$ in DPD-HighPB to a high of $62 \%$ in DD-LowPB. Consistent with behavior observed in other experimental CPR and public good studies, efficiency levels are generally well above $0 \%$, but also well below the social optimum. As one might expect, for symmetric decision settings lower $P B$ values result in higher efficiency in DD and DPD game settings. Moreover, the probability of degradation leads to reductions in efficiencies when comparing DPD to DD game settings, despite the lower average appropriation in the DPD game. Thus, subjects do not to sufficiently reduce appropriation levels to offset the reduction in efficiency imposed by the expected degradation of the Group Fund in the DPD game settings.

\section{Discussion and conclusion}

This study complements the earlier experimental literature on social dilemmas by examining the mediating effect of endogenous probabilistic degradation externalities on appropriation decisions under varying opportunity costs from cooperation, including both symmetric and asymmetric settings. This research is particularly relevant to understanding behavioral responses to changes in incentives for the conservation of ecosystem services associated with the maintenance of natural resources in settings where group cooperation determine the emergence of probabilistic losses. Salient examples are climate change mitigation and conservation of biodiversity.

The results support the conclusion that the higher the private marginal incentives to appropriate, the higher the appropriation levels, resulting in lower efficiency in use of the resource. By extending the scope of analysis to appropriation games, as well a setting that does 
not allow for group dynamics nor opportunities for signaling cooperative intentions, this result provides a robustness test of the findings from the public goods literature on the role of MPCR in determining levels of cooperation. Further, as conjectured, for the same marginal incentives, appropriation levels in symmetric and asymmetric settings are not significantly different. This finding supports the observation by Fisher et al. (1995) and Margreiter et al (2005) that subjects appear to respond primarily to their own marginal benefits.

In comparing settings with both deterministic and probabilistic degradation to those with only deterministic degradation, subjects who believe that the shared resource will be substantially exploited, and therefore benefits from their own conservation rather small, face stronger marginal incentives to appropriate. The results show that these subjects appropriate at higher levels in decision settings with probabilistic degradation. The opposite holds true for subjects who believe that other group members will refrain from appropriation and manage to sustain the resource at a high level. Thus, evidence is found that subjects' first order beliefs condition their responses to probabilistic degradation. In addition, relative to actual appropriation levels in the experiment, forecasts of others' appropriation on average are biased upwards, revealing a tendency for pessimism regarding the expected cooperativeness of other group members. Even with this upward bias in expectations, average group appropriation is lower in games that include probabilistic degradation. Thus, introducing probabilistic degradation increases average cooperation. This increased cooperation, however, is not large enough to offset losses in expected efficiency due to probabilistic degradation.

This study builds on earlier experimental studies on social dilemmas by examining a stark institutional setting where users are not capable of adopting institutions that facilitate cooperation over time. Gaining an understanding of individual responses to changes in the 
relative value of the resource, and consequently the opportunity cost of conservation, as well as responses to the introduction of probabilistic losses, is fundamental in designing programs whose intention is to ameliorate inefficiencies and/or avoid the destruction of natural resources and the ecosystem services provided by the resource.

\section{Notes}

\footnotetext{
${ }^{1}$ Also see the Economics of Ecosystems and Biodiversity global initiative [http://www.teebweb.org/]; the UK National Ecosystem Assessment [http://uknea.unep-wcmc.org ]; the Millennium Ecosystem Assessment [http://www.unep.org/maweb/]; or the Ecosystem Services for Poverty Alleviation [http://www.espa.ac.uk/]. ${ }^{2}$ It might be argued that equivalent information could be derived from decisions in the first round of a repeated game. Yet, the first-round decision of subjects in this context might be confounded with strategic signaling of willingness to engage in cooperative play.

${ }^{3}$ This game builds on the appropriation game presented by Cox et al (2013). Other studies using similar games but addressing framing differences between linear provision and appropriation games are Andreoni (1995), Sonnemans
} et al. (1998) and Dufwenberg et al. (2011).

${ }^{4}$ A $50 \%$ reduction in the value of the Group Fund was implemented to avoid the extreme case of a $100 \%$ reduction, while maintaining a reduction that had important implications for experimental earnings. In addition, for experimental control and simplicity, the capacity to appropriate (e) was set equal to 25 , as described in section 2.3 . Therefore, if all subjects appropriate up to their capacity, the result is a $100 \%$ chance of probabilistic degradation. Note, therefore, that the parameters of the DPD game imply settings with substantial probabilistic losses.

${ }^{5}$ Other, less similar, experimental settings provide further evidence related to heterogeneities and levels of cooperation (see Marwell and Ames 1979; Ahn et al. 2007; Reuben and Riedl 2009).

${ }^{6}$ Note that although the DPD game has two Nash equilibria when $P B=0.6$, the minimum and maximum possible group payoffs used for calculating efficiency are not affected. The minimum payoffs are still those of the Nash equilibrium with appropriation up to capacity.

${ }^{7}$ Examining the effects of asymmetries in appropriation games has focused primarily on players' positions rather than marginal incentives. Hackett et al. (1994) and Holahan (2011) examine CPR settings where subjects have 
communication or voting opportunities to facilitate cooperation, where subjects receive differential returns from agreements that are linked to the capacity to appropriate. Cardenas et al. (2011) and Janssen et al. (2012) examine settings where CPR users face sequential decisions, introducing asymmetries through the position (order) each subject has in making appropriation decisions.

${ }^{8}$ Average earnings (in US\$), including the forecast bonus, were for the DD games 13.96 (DD-MedPB), 14.83 (DD-HighPB), 13.40 (DD-LowPB), 16.22 (DD-Asym(PB=1.4)), and 11.36 (DD-Asym(PB=0.6)). For the DPD games, average earnings, with the forecast bonus, were 9.71 (DPD-MedPB), 11.61 (DPD-HighPB), 9.36 (DPDLowPB), 11.71 (DPD-Asym( $\mathrm{PB}=1.4)$ ), and 7.44 (DPD-Asym( $\mathrm{PB}=0.6)$ ). In addition to these experimental earnings, subjects received a show-up payment of $\$ 2.83$.

${ }^{9}$ Using our notation, the baseline appropriation game of Cox et al. (2013) is parameterized with $P B=1$ and $g=3$. Based on the relative value of $g / P B=3 / 1$, our decision setting LowPB (where $g / h=2 / 0.6=3.33$ ) comes closest to matching the marginal incentives in their appropriation game. Cox et al. observe an average individual appropriation of $38.1 \%$ of maximum appropriation capacity, nearly identical to the $37.8 \%$ observed in LowPB decision setting in our study.

${ }^{10}$ Across all decision settings, $18.26 \%$ of the forecasts of the per-person appropriation of other group members are identical to the decision makers' own decision. Table 2 shows that the mean forecasts of others' individual appropriation levels (potentially ranging between $0-25$ ) follow a pattern across decision settings that is very similar to the pattern observed for average individual appropriation levels. However, across all decision settings, there is a clear "upward shift" in average per-person forecasts relative to actual appropriation levels. Thus, on average subjects' beliefs of the cooperative behavior of other group members are overly pessimistic. Further, for the same value of $P B$, forecasts for symmetric and asymmetric decisions are very similar; and lower for the DPD games relative to the DD games.

${ }^{11}$ Other results regarding the average group effect in asymmetric decision settings are somewhat mixed. As shown in Table 3 panel A for the DD game, average appropriation in the asymmetric decision settings with an average value of $P B=1$ (DD-Asym(pooled $\mathrm{PB}$ )) is not statistically different to that of symmetric decision settings where $P B=1$ (DD-MedPB). However, for the same decision settings in the DPD game, as shown in Table 3 panel B, there is a weakly significant effect (at the $10 \%$ level of significance) due to asymmetry, with average appropriation being higher in the asymmetric decision setting. 
${ }^{12}$ Based on the first order beliefs, for the DPD games, the percentage of subjects that forecasted a group appropriation greater than 50 tokens is $26.56 \%$ for DPD-LowPB, $39.84 \%$ for DPD-MedPB, $53.13 \%$ for DPDHighPB, 20.31\% for DPD-Asym(PB=0.6) and 20.31\% for DPD-Asym(PB=1.4)

${ }^{13}$ For the asymmetric treatment condition DPD-Asym(pooled), individual specific $P B$ values were used for computing $\mathrm{MNB}_{\mathrm{i}}^{\prime}$. The results for the perceived $\mathrm{MNB}_{\mathrm{i}}^{\prime}$ at the individual level are robust to computing the value of the $\mathrm{MNB}_{\mathrm{i}}^{\prime}$ based only on forecasts of the other 3 group members' appropriation.

14 In order to assess the potential existence of interaction effects between asymmetry and probabilistic degradation, an additional analysis for the pooled asymmetric treatment was conducted that included a dummy variable for low- $P B$, the continuous variable $\mathrm{MNB}_{\mathrm{i}}^{\prime}$, and the interaction of these two variables. As expected, the coefficients found in this analysis correspond to those presented in columns 4 and 5 of Table 6 . The constant term and the coefficients for the low- $P B$ dummy and the $\mathrm{MNB}_{\mathrm{i}}^{\prime}$ variable are statistically significant. The interaction term, however, is not significant. Thus, the latter result does not support the existence of robust differential responses to $\mathrm{MNB}_{\mathrm{i}}^{\prime}$ between high and low- $P B$ subjects in the asymmetric treatments. 


\section{References}

Ahn, T. K., Lee, M, Ruttan, L., Walker, J. M. (2007) Asymmetric Payoffs in Simultaneous and Sequential Prisoner's Dilemma Games. Public Choice 132: 353-366.

Andreoni, J. (1995) Warm Glow versus Cold Prickle: The Effects of Positive and Negative Framing on Cooperation in Experiments. Quarterly Journal of Economics 110: 2-20.

Bagnoli, M., McKee, M. (1991) Voluntary Contribution Games: Efficient Private Provision of Public Goods. Economic Inquiry 29: 351-366.

Barrett, S., Dannenberg, A. (2012) Climate negotiations under scientific uncertainty. PNAS 109: 17372-17376.

Brandts, J., Schram, A. (2001) Cooperation and Noise in Public Goods Experiments: Applying the Contribution Function Approach. Journal of Public Economics 79: 399-427.

Camerer, C. F. (2003) Behavioral Game Theory: Experiments in Strategic Interaction. Princeton University Press, Princeton, NJ.

Camerer, C. F., Fehr, E. (2006) When Does ‘Economic Man’ Dominate Social Behavior? Science 311: 47-52.

Cardenas, J. C., Rodriguez, L. A., Johnson, N. (2011) Collective Action for Watershed Management: Field Experiments in Colombia and Kenya. Environment and Development Economics 16: 275-303.

Chan, K., Mestelman, S., Moir, R., Muller, R. A. (1999) Heterogeneity and the Voluntary Provision of Public Goods. Experimental Economics 2: 5-30.

Chaudhuri, A. (2011). Sustaining cooperation in laboratory public goods experiments: a selective survey of the literature. Experimental Economics 14, 47-83. 
Costanza, R., d'Arge, R., de Groot, R., Farber, S., Grasso, M., Hannon, B., Limburgstar, K., Naeem, S., O’Neill, R.V., Paruelo, J., Raskin, R.G., Sutton, P., van den Belt, M. (1997) The Value of the World's Ecosystem Services and Natural Capital. Nature 387: 253-260. Cox, J., Friedman, D., Sadiraj, V. (2008) Revealed Altruism. Econometrica 76: 31-69. Cox, J., Ostrom, E., Sadiraj, V., Walker, J. M. (2013) Provision versus Appropriation in Symmetric and Asymmetric Social Dilemmas. Southern Economic Journal 79: 496-512. Croson, R. (2007) Theories of Commitment, Altruism, and Reciprocity: Evidence from Linear Public Goods Games. Economic Inquiry 45: 199-216.

Dickinson, D.L. (1998) The Voluntary Contributions Mechanism with Uncertain Group Payoffs. Journal of Economic Behavior and Organization 35: 517-33.

Dufwenberg, M., Gachter, S., Henig-Schmidt, H. (2011) The framing of games and the psychology of play, Games and Economic Behavior 73: 459-478.

Falkinger, J., Fehr, E., Gächter, S., Winter-Ebmer, R. (2000) A Simple Mechanism for the Efficient Provision of Public Goods: Experimental Evidence. The American Economic Review, 90: 247-264.

Fehr, E., Schmidt, K. (1999) Theory of Fairness, Competition, and Cooperation. Quarterly Journal of Economics 114: 817-868.

Fisher, J., Isaac, R. M., Schatzerg, J., Walker, J. M., (1995). Heterogeneous Demand for Public Goods: Effects on the Voluntary Contributions Mechanism. Public Choice 85, 249-266. Fischbacher, U., Gächter, S., Fehr, E. (2001) Are People Conditionally Cooperative? Evidence from a Public Goods Experiment. Economics Letter 71: 397-404.

Fischbacher, U., Schudy, S., Teyssier, S. (forthcoming) Heterogeneous Reactions to Heterogeneity in Returns from Public Goods. Social Choice and Welfare. 
Gangadharan, L., Nemes, V. (2009) Experimental Analysis of Risk and Uncertainty in Provisioning Private and Public Goods. Economic Inquiry 47: 146-164.

Gordon, H. S. (1954) The Economic Theory of a Common Property Resource: The Fishery. Journal of Political Economy 62: 124-142.

Hackett, S., Schlager, E., Walker, J. M. (1994) The Role of Communication in Resolving Commons Dilemmas: Experimental Evidence with Heterogeneous Appropriators. Journal of Environmental Economics and Management 27: 99-126.

Hardin, G. (1968) The Tragedy of the Commons. Science 162: 1243-1248.

Holahan, R. (2011) Collective Action and Heterogeneous Capacity in the Commons: An Experimental Study. Working Paper.

Isaac, R. M., Walker, J. M., Williams, A. (1994) Group Size and the Voluntary Provision of Public Goods: Experimental Evidence Utilizing Large Groups. Journal of Public Economics 54: 1-36.

Janssen, M. A., Bousquet, F., Cardenas, J. C., Castillo, D., Worrapimphong, K. (2012) Field Experiments on Irrigation Dilemmas. Agricultural Systems 109: 65-75.

Ledyard, J. (1995) Public Goods: A Survey of Experimental Research. In J. Kagel \& A. Roth (eds), Handbook of Experimental Economics. Princeton, NJ: Princeton University Press.

Margreiter, M.,Sutter, M., Dittrich, D. (2005) Individual and Collective Choice and Voting in Common Pool Resource Problem with Heterogeneous Actors. Environmental and Resource Economics 32: 241-271.

Marwell, G., Ames, R. E. (1979) Experiments on the Provision of Public Goods. I. Resources, Interest, Group Size, and the Free-Rider Problem. American Journal of Sociology 84: $1335-1360$. 
Milinski,M., Sommerfeld,R.D., Krambeck,H.J., Reed,F.A., and Marotzke, J. (2008) The collective-risk social dilemma and the prevention of simulated dangerous climate change PNAS 105: 2291-2294.

Nikiforakis, N., Noussair, C. N., Wilkening,T. (2012) Normative Conflict and Feuds: The Limits of Self-Enforcement. Journal of Public Economics 96: 797-807.

Noussair, C. N., Tan, F. (2011) Voting on Punishment Systems within a Heterogeneous Group. Journal of Public Economic Theory 13: 661-693.

Offerman, T., Sonnemans, J., Schram, A. (1996) Value Orientations, Expectations and Voluntary Contributions in Public Goods. The Economic Journal 106: 817-845.

Ostrom, E., Walker, J. M., (eds) (2003) Trust and Reciprocity: Interdisciplinary Lessons from Experimental Eesearch. Russell Sage Foundation, New York.

Ostrom, E. (2009) A General Framework for Analyzing Sustainability of Social-Ecological Systems. Science 325, 419-422.

Reuben, E., Riedl, A. (2009) Public Goods Provision and Sanctioning in Privileged Groups. Journal of Conflict Resolution 53: 72-93.

Reuben, E., Riedl, A. (2013) Enforcement of Contribution Norms in Public Good Games with Heterogeneous Populations. Games and Economic Behavior 77: 122-137.

Schröter, D., Cramer, W., Leemans, R., Prentice, I.C., Araújo, M.B., Arnell, N.W., Bondeau, A., Bugmann, H., Carter, T.R., Gracia, C.A., de la Vega-Leinert, A.C., Erhard, M., Ewert, F., Glendining, M., House, J.I., Kankaanpää, S., Klein, R.J.T., Lavorel, S., Lindner, M., Metzger, .J., Meyer, J., Mitchell, T.D., Reginster, I., Rounsevell, M., Sabaté, S., Sitch, S., Smith, B., Smith, J., Smith, P., Sykes, M.T., Thonicke, K., Thuiller, W., Tuck, G., 
Zaehle, S., Zierl, B. (2005) Ecosystem Service Supply and Vulnerability to Global Change in Europe. Science: 310, 1333 -1337.

Sonnemans, J., Schram, A., Offerman, T. (1998) Public Good Provision and Public Bad Prevention: The Effect of Framing. Journal of Economic Behavior and Organization 34: $143-161$.

Tan, F. (2008) Punishment in a Linear Public Good Game with Productivity Heterogeneity. De Economist 156: 269-293.

Walker, J. M., Gardner, R. (1992) Probabilistic Destruction of Common-Pool Resources: Experimental Evidence. The Economic Journal 102, 1149-1161. 
PANEL A

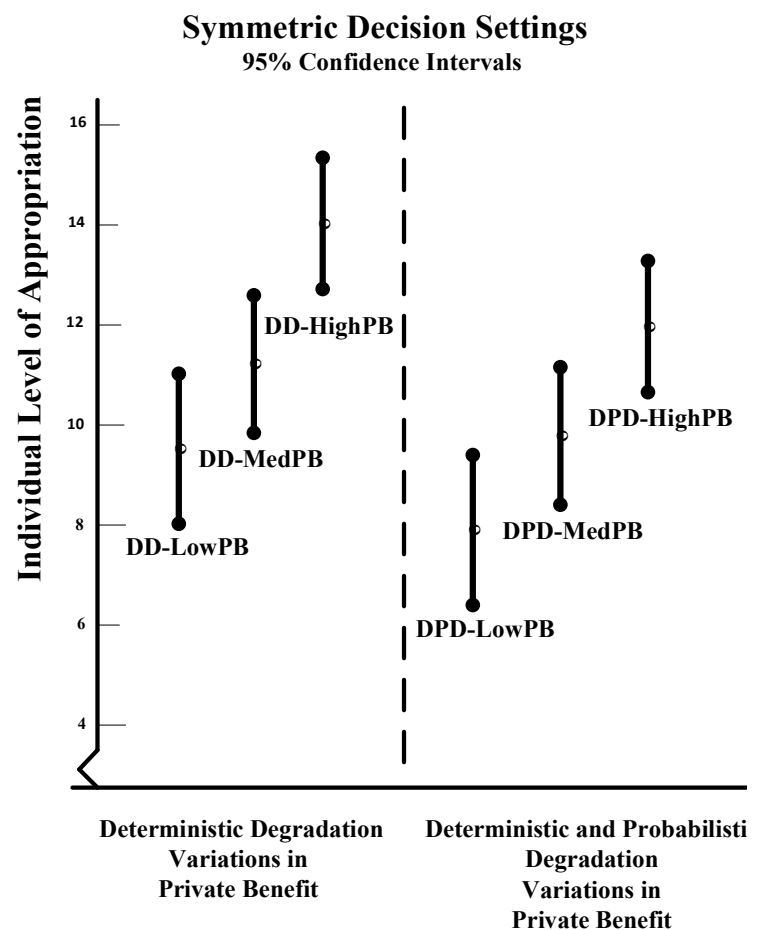

PANEL B

\section{Asymmetric Decision Settings}

95\% Confidence Intervals

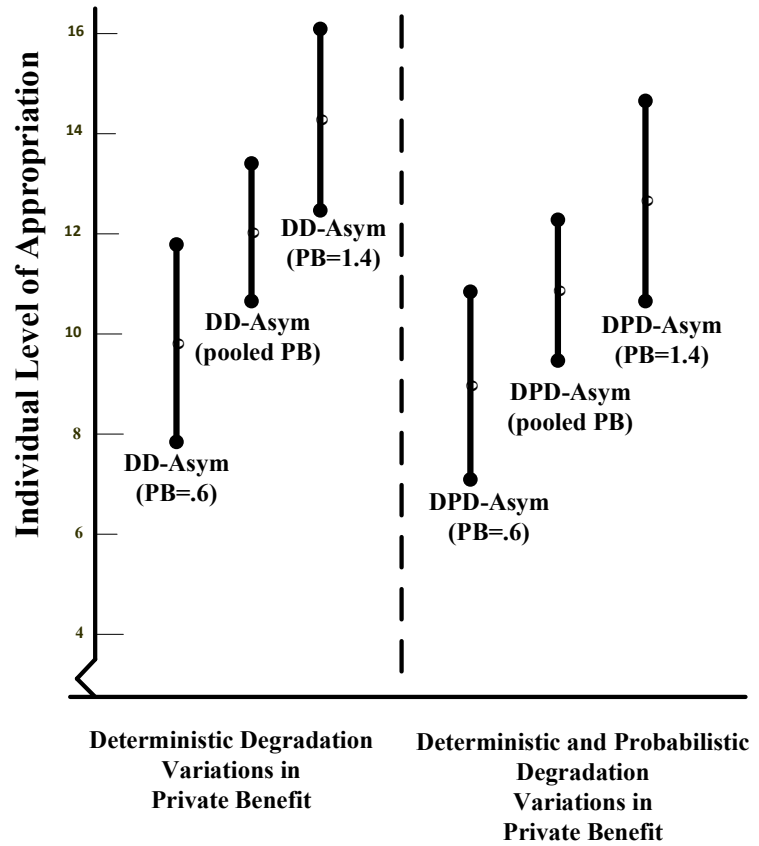

Figure 1. Appropriation as a function of private benefits

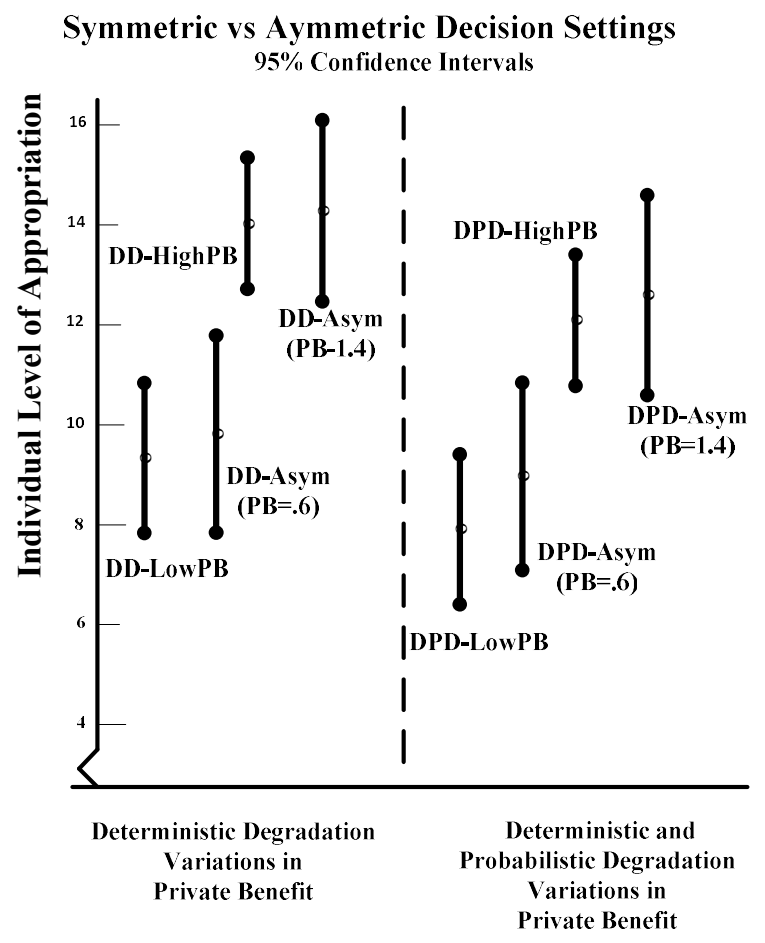

Figure 2. Contrasting appropriation in symmetric and asymmetric decision settings 
Table 1. Decision Settings: names and parameters

\begin{tabular}{|c|c|c|c|}
\hline \multicolumn{4}{|c|}{ DD Games } \\
\hline $\begin{array}{l}\text { Decision } \\
\text { Setting }\end{array}$ & $\begin{array}{l}\text { Group Fund } \\
\text { value: } g\end{array}$ & $\begin{array}{l}\text { Private Fund } \\
\text { value: } P B\end{array}$ & $\begin{array}{l}\text { Marginal net benefit from appropriation } \\
\qquad(\mathrm{MNB})\end{array}$ \\
\hline DD-MedPB & 2 & 1 & 0.5 \\
\hline DD-HighPB & 2 & 1.4 & 0.9 \\
\hline DD-LowPB & 2 & 0.6 & 0.1 \\
\hline $\begin{array}{l}\text { DD-Asym } \\
\text { (pooled PB) }\end{array}$ & 2 & $\begin{array}{c}1.4 \text { or } 0.6 \\
\text { (average } 1)\end{array}$ & $\begin{array}{c}0.9 \text { or } 0.1 \\
\text { (average } 0.5)\end{array}$ \\
\hline \multicolumn{4}{|c|}{ DPD Games } \\
\hline $\begin{array}{l}\text { Decision } \\
\text { Setting }\end{array}$ & $\begin{array}{l}\text { Group Fund } \\
\text { value: } g\end{array}$ & $\begin{array}{l}\text { Private Fund } \\
\text { value: } P B\end{array}$ & $\begin{array}{l}\text { Marginal net benefit from appropriation } \\
\text { (MNB) }\end{array}$ \\
\hline DPD-MedPB & 2 & 1 & $0.5-0.0025\left(100-2 \sum_{i=1}^{n} z_{i}\right)$ \\
\hline DPD-HighPB & 2 & 1.4 & $0.9-0.0025\left(100-2 \sum_{i=1}^{n} z_{i}\right)$ \\
\hline DPD-LowPB & 2 & 0.6 & $0.1-0.0025\left(100-2 \sum_{i=1}^{n} z_{i}\right)$ \\
\hline $\begin{array}{l}\text { DPD-Asym } \\
\text { (pooled PB) }\end{array}$ & 2 & $\begin{array}{c}1.4 \text { or } 0.6 \\
\text { (average } 1 \text { ) }\end{array}$ & $(0.9$ or 0.1$)-0.0025\left(100-2 \sum_{i=1}^{n} z_{i}\right)$ \\
\hline
\end{tabular}

Marginal net gains are calculated using equations 2 and 4 with the specific parameter values in each decision setting for $P B$, as well as, $\mathrm{L}=50 \%, \mathrm{p}=1 \%, \mathrm{t}=100$, and $\mathrm{g} / \mathrm{n}=0.5$. 
Table 2. Individual and group level appropriation, efficiency and forecasts

\begin{tabular}{|c|c|c|c|c|c|c|}
\hline \multicolumn{7}{|c|}{ PANEL A - DD Games } \\
\hline $\begin{array}{l}\text { Decision } \\
\text { Settting }\end{array}$ & $\begin{array}{l}\text { Average individual } \\
\text { appropriation } \\
(0-25 \text { tokens })\end{array}$ & $\begin{array}{l}\text { Average group } \\
\text { appropriation } \\
(0-100 \text { tokens })\end{array}$ & $\begin{array}{l}\text { Frequency of } \\
\text { maximum } \\
\text { allowable } \\
\text { appropriation }\end{array}$ & $\begin{array}{l}\text { Frequency of } \\
\text { zero } \\
\text { appropriation }\end{array}$ & $\begin{array}{l}\text { Average } \\
\text { Efficiency } \\
(0-100 \%)\end{array}$ & $\begin{array}{c}\text { Forecast of } \\
\text { individual } \\
\text { appropriation } \\
\text { (0-25 tokens) }\end{array}$ \\
\hline DD-MedPB & $11.27(8.71)$ & $45.09(17.83)$ & $14.06 \%$ & $17.97 \%$ & $54.91 \%$ & $13.00(6.75)$ \\
\hline DD-HighPB & $14.07(8.96)$ & $56.28(21.34)$ & $23.44 \%$ & $9.38 \%$ & $43.72 \%$ & $15.28(6.94)$ \\
\hline DD-LowPB & $9.44(8.95)$ & $37.75(16.39)$ & $10.94 \%$ & $28.91 \%$ & $62.25 \%$ & $10.38(6.49)$ \\
\hline $\begin{array}{l}\text { DD-Asym } \\
\text { (pooled PB) }\end{array}$ & $\begin{array}{c}12.21(8.91) \\
\text { for } P B_{i}=1.4 \\
14.45(8.44) \\
\text { for } P B_{i}=0.6 \\
9.97(8.86)\end{array}$ & 48.84 (18.19) & $\begin{array}{c}17.97 \% \\
\text { for } P B_{i}=1.4 \\
25 \% \\
\text { for } P B_{i}=0.6 \\
10.94 \%\end{array}$ & $\begin{array}{c}13.28 \% \\
\text { for } P B_{i}=1.4 \\
4.69 \% \\
\text { for } P B_{i}=0.6 \\
21.88 \%\end{array}$ & $54.74 \%$ & $\begin{array}{c}12.86(6.12) \\
\text { for } P B_{i}=1.4 \\
15.15(7.26) \\
\text { for } P B_{i}=0.6 \\
10.57(6.88)\end{array}$ \\
\hline \multicolumn{7}{|c|}{ PANEL B - DPD Games } \\
\hline $\begin{array}{l}\text { Decision } \\
\text { Setting }\end{array}$ & $\begin{array}{l}\text { Average individual } \\
\text { appropriation } \\
(0-25 \text { tokens })\end{array}$ & $\begin{array}{l}\text { Average group } \\
\text { appropriation } \\
(0-100 \text { tokens })\end{array}$ & $\begin{array}{l}\text { Frequency of } \\
\text { maximum } \\
\text { allowable } \\
\text { appropriation }\end{array}$ & $\begin{array}{l}\text { Frequency of } \\
\text { zero } \\
\text { appropriation }\end{array}$ & $\begin{array}{l}\text { Average } \\
\text { Efficiency } \\
(0-100 \%)\end{array}$ & $\begin{array}{c}\text { Forecast of } \\
\text { individual } \\
\text { appropriation } \\
\text { (0-25 tokens) }\end{array}$ \\
\hline DPD-MedPB & $9.80(8.31)$ & $39.22(18.46)$ & $9.38 \%$ & $22.66 \%$ & $36.94 \%$ & $11.31(6.55)$ \\
\hline DPD-HighPB & $12.03(8.59)$ & $48.13(17.93)$ & $16.41 \%$ & $11.72 \%$ & $10.26 \%$ & $13.16(6.67)$ \\
\hline DPD-LowPB & $7.86(8.29)$ & $31.44(16.83)$ & $7.81 \%$ & $32.03 \%$ & $53.16 \%$ & $9.76(6.81)$ \\
\hline $\begin{array}{l}\text { DPD-Asym } \\
\text { (pooled PB) }\end{array}$ & $\begin{array}{c}10.81(8.46) \\
\text { for } P B_{i}=1.4 \\
12.66(8.11) \\
\text { for } P B_{i}=0.6 \\
8.97(8.46)\end{array}$ & $43.25(16.31)$ & $\begin{array}{c}9.38 \% \\
\text { for } P B_{i}=1.4 \\
\quad 9.38 \% \\
\text { for } P B_{i}=0.6 \\
\quad 9.38 \%\end{array}$ & $\begin{array}{c}16.41 \% \\
\text { for } P B_{i}=1.4 \\
4.69 \% \\
\text { for } P B_{i}=0.6 \\
28.12 \%\end{array}$ & $35.15 \%$ & $\begin{array}{c}11.47(6.24) \\
\text { for } P B_{i}=1.4 \\
13.27(6.92) \\
\text { for } P B_{i}=0.6 \\
9.67(7.04)\end{array}$ \\
\hline
\end{tabular}

Standard deviations in parentheses.

Group appropriation is based on groups formed randomly at the beginning of the experiment. Group composition is the same for all decision settings. 
Table 3. Differences in means and paired t-test comparisons between decision settings.

\begin{tabular}{|c|c|c|c|c|}
\hline \multicolumn{5}{|c|}{ PANEL A - DD Games } \\
\hline Individual decisions & DD-LowPB & DD-MedPB & DD-HighPB & DD-Asym(PB=0.6) \\
\hline DD-LowPB & --- & & & \\
\hline DD-MedPB & $\begin{array}{c}1.836 \\
t=3.053(0.003)\end{array}$ & --- & & \\
\hline DD-HighPB & $\begin{array}{c}4.633 \\
\mathrm{t}=5.987(0.000)\end{array}$ & $\begin{array}{c}2.797 \\
t=4.935(0.000)\end{array}$ & --- & \\
\hline $\mathrm{DD}-\operatorname{Asym}(\mathrm{PB}=0.6)^{\mathrm{c}}$ & $\begin{array}{c}0.516 \\
t=1.606(0.113)\end{array}$ & $\begin{array}{c}-1.469 \\
\mathrm{t}=-3.360(0.001)\end{array}$ & $\begin{array}{c}-3.640 \\
\mathrm{t}=-3.360(0.001)\end{array}$ & --- \\
\hline $\mathrm{DD}-\operatorname{Asym}(\mathrm{PB}=1.4)^{\mathrm{c}}$ & $\begin{array}{c}5.031 \\
\mathrm{t}=5.019(0.000)\end{array}$ & $\begin{array}{c}3.344 \\
\mathrm{t}=4.896(0.000)\end{array}$ & $\begin{array}{c}0.0781 \\
t=0.135(0.893)\end{array}$ & $\begin{array}{c}4.484 \\
t=2.931^{\mathrm{a}}(0.004)\end{array}$ \\
\hline DD-Asym(pooled PB) & $\begin{array}{c}2.773 \\
\mathrm{t}=4.384(0.000)\end{array}$ & $\begin{array}{c}0.938 \\
t=1.544(0.125)\end{array}$ & $\begin{array}{c}-1.859 \\
\mathrm{t}=-2.941(0.004)\end{array}$ & $---{ }^{b}$ \\
\hline \multicolumn{5}{|c|}{ PANEL B - DPD Games } \\
\hline Individual decisions & DPD-LowPB & DPD-MedPB & DPD-HighPB & DPD-Asym $(\mathrm{PB}=0.6)$ \\
\hline DPD-LowPB & --- & & & \\
\hline DPD-MedPB & $\begin{array}{c}1.945 \\
t=3.566(0.000)\end{array}$ & --- & & \\
\hline DPD-HighPB & $\begin{array}{c}4.172 \\
\mathrm{t}=5.665(0.000)\end{array}$ & $\begin{array}{c}2.227 \\
\mathrm{t}=4.340(0.000)\end{array}$ & --- & \\
\hline $\operatorname{DPD}-\operatorname{Asym}(\mathrm{PB}=0.6)^{\mathrm{c}}$ & $\begin{array}{c}1.063 \\
t=1.304(0.197)\end{array}$ & $\begin{array}{c}-0.875 \\
\mathrm{t}=-1.169(0.247)\end{array}$ & $\begin{array}{c}-3.047 \\
\mathrm{t}=-2.823(0.006)\end{array}$ & --- \\
\hline $\operatorname{DPD}-\operatorname{Asym}(\mathrm{PB}=1.4)^{\mathrm{c}}$ & $\begin{array}{c}4.844 \\
\mathrm{t}=4.848(0.000)\end{array}$ & $\begin{array}{c}2.891 \\
\mathrm{t}=4.007(0.000)\end{array}$ & $\begin{array}{c}0.609 \\
t=1.120(0.267)\end{array}$ & $\begin{array}{c}3.688 \\
t=2.516^{a}(0.013)\end{array}$ \\
\hline DPD-Asym(pooled PB) & $\begin{array}{c}2.953 \\
\mathrm{t}=4.450(0.000)\end{array}$ & $\begin{array}{c}1.008 \\
t=1.853(0.066)\end{array}$ & $\begin{array}{c}-1.219 \\
\mathrm{t}=-1.955(0.053)\end{array}$ & $---b$ \\
\hline
\end{tabular}

$\mathrm{p}$ - values in parenthesis. Differences in means are constructed from the perspective of the treatment outcome in the row cell minus the treatment outcome in the corresponding column cell.

${ }^{a}$ Given the experimental design, these t-tests are based on differences in unpaired means. Individual subjects did not participate in both the high and low $P B$ conditions in the asymmetric treatments.

${ }^{\mathrm{b}}$ These comparisons do not apply. The DD-Asym(pooled PB) and DPD-Asym(pooled PB) are constructed with the decisions of subjects from the low and high

$P B$ values in the asymmetric treatments.

${ }^{\mathrm{c}}$ The computations in these rows are based on 64 observations per sample. In the asymmetric treatment conditions, half of the subjects were in the low $P B$ condition and half were in the high $P B$ condition. 
Table 4. Differences in means and paired t-tests between individual appropriation in DPD and DD games.

\begin{tabular}{l|llllll}
\hline \hline & $\begin{array}{l}\text { DPD-DD } \\
\text { LowPB }\end{array}$ & $\begin{array}{l}\text { DPD-DD } \\
\text { MedPB }\end{array}$ & $\begin{array}{l}\text { DPD-DD } \\
\text { HighPB }\end{array}$ & $\begin{array}{l}\text { DPD-DD } \\
\text { Asym } \\
(\mathrm{PB}=0.6)\end{array}$ & $\begin{array}{l}\text { DPD-DD } \\
\text { Asym } \\
(\mathrm{PB}=1.4)\end{array}$ & $\begin{array}{l}\text { DPD-DD } \\
\text { Asym } \\
\text { (pooled PB) }\end{array}$ \\
\hline \hline $\begin{array}{l}\text { Mean } \\
\text { difference }\end{array}$ & -1.578 & -1.469 & -2.039 & -1.000 & -1.797 & -1.398 \\
paired t-tests & $\begin{array}{llll}\mathrm{t}=-2.339 \\
\mathrm{t}=-1.957\end{array}$ & $\begin{array}{l}\mathrm{t}=-3.128 \\
(0.002)\end{array}$ & $\begin{array}{l}\mathrm{t}=-1.163 \\
(0.249)\end{array}$ & $\begin{array}{l}\mathrm{t}=-1.897 \\
(0.062)\end{array}$ & $\begin{array}{l}\mathrm{t}=-2.192 \\
(0.030)\end{array}$ \\
\hline Observations & 128 & 128 & 128 & 64 & 64 & 128 \\
\hline \hline
\end{tabular}

Table 5. OLS: dependent variable — Difference in individual appropriation DPD-DD

\begin{tabular}{l|llllll}
\hline \hline & $\begin{array}{l}\text { DPD-DD } \\
\text { LowPB }\end{array}$ & $\begin{array}{l}\text { DPD-DD } \\
\text { MedPB }\end{array}$ & $\begin{array}{l}\text { DPD-DD } \\
\text { HighPB }\end{array}$ & $\begin{array}{l}\text { DPD-DD } \\
\text { Asym } \\
(\mathrm{PB}=0.6)\end{array}$ & $\begin{array}{l}\text { DPD-DD } \\
\text { Asym } \\
(\mathrm{PB}=1.4)\end{array}$ & $\begin{array}{l}\text { DPD-DD } \\
\text { Asym } \\
\text { (pooled PB) }\end{array}$ \\
\hline \hline Intercept & $\begin{array}{l}-2.543 \\
(0.001)\end{array}$ & $\begin{array}{l}-3.844 \\
(0.000)\end{array}$ & $\begin{array}{l}-5.050 \\
(0.000)\end{array}$ & $\begin{array}{l}-2.073 \\
(0.055)\end{array}$ & $\begin{array}{l}-3.632 \\
(0.003)\end{array}$ & $\begin{array}{l}-2.823 \\
(0.000)\end{array}$ \\
DUM>50 & $\begin{array}{l}3.631 \\
(0.017)\end{array}$ & $\begin{array}{l}5.962 \\
(0.000)\end{array}$ & $\begin{array}{l}5.668 \\
(0.000)\end{array}$ & $\begin{array}{l}2.986 \\
(0.096)\end{array}$ & $\begin{array}{l}4.516 \\
(0.018)\end{array}$ & $\begin{array}{l}(0.721 \\
(0.004)\end{array}$ \\
\hline Observations & 128 & 128 & 128 & 64 & 64 & 128 \\
$\mathrm{R}^{2}$ & 0.045 & 0.119 & 0.148 & 0.044 & 0.087 & 0.063 \\
\hline \hline p-values in parentheses & & & & & &
\end{tabular}

Table 6. OLS: dependent variable - Difference in individual appropriation DPD-DD

\begin{tabular}{|c|c|c|c|c|c|c|}
\hline & $\begin{array}{l}\text { DPD-DD } \\
\text { LowPB }\end{array}$ & $\begin{array}{l}\text { DPD-DD } \\
\text { MedPB }\end{array}$ & $\begin{array}{l}\text { DPD-DD } \\
\text { HighPB }\end{array}$ & $\begin{array}{l}\text { DPD-DD } \\
\text { Asym } \\
(\mathrm{PB}=0.6)\end{array}$ & $\begin{array}{l}\text { DPD-DD } \\
\text { Asym } \\
(\mathrm{PB}=1.4)\end{array}$ & $\begin{array}{l}\text { DPD-DD } \\
\text { Asym } \\
\text { (pooled PB) }\end{array}$ \\
\hline Intercept & $\begin{array}{l}-2.132 \\
(0.002)\end{array}$ & $\begin{array}{l}-13.743 \\
(0.000)\end{array}$ & $\begin{array}{l}-19.667 \\
(0.000)\end{array}$ & $\begin{array}{c}-1.851 \\
(0.068)\end{array}$ & $\begin{array}{c}-18.828 \\
(0.006)\end{array}$ & $\begin{array}{l}-1.587 \\
(0.104)\end{array}$ \\
\hline$M N B_{i}^{\prime}$ & $\begin{array}{l}15.544 \\
(0.002)\end{array}$ & $\begin{array}{l}26.188 \\
(0.000)\end{array}$ & $\begin{array}{l}19.425 \\
(0.000)\end{array}$ & $\begin{array}{l}11.149 \\
(0.108)\end{array}$ & $\begin{array}{l}19.352 \\
(0.012)\end{array}$ & $\begin{array}{c}0.395 \\
(0.796)\end{array}$ \\
\hline Observations & 128 & 128 & 128 & 64 & 64 & 128 \\
\hline $\mathrm{R}^{2}$ & 0.074 & 0.159 & 0.118 & 0.041 & 0.099 & 0.001 \\
\hline
\end{tabular}

p-values in parentheses 


\section{Appendix A: Instructions}

\section{WELCOME}

The instructions which follow describe 8 decision making situations ( 1 to 8 ). Please read the instructions carefully, as your decisions and the decisions of others in the experiment will affect your final earnings.

No Talking Allowed

Now that the experiment has begun, we ask that you do not talk. If you have a question after reading the instructions, please raise your hand and the monitor will approach you and answer your question in private. After being seated a packet with instructions will be distributed to each person. In your packet you will find your participant number. Your number is your private information; do not display it to other participants.

\section{Experiment Instructions}

In this experiment, you will make choices in 8 independent decision situations. After the experiment is over, we will randomly pick only one of the 8 decision situations for computing your cash earnings.

- You will receive specific instructions for each decision situation.

- Before making decisions for each decision situation, you will answer a short quiz designed to check your understanding of the decision situations. After all participants finish each quiz the monitor will provide the solutions in public and answer questions privately.

- At any point during decision-making, you will have the opportunity to review and (if you wish) change any of the choices that you have already made. After all participants have had time to finalize their decisions, the monitor will announce the end of the experiment, after which no one will be allowed to change their decisions.

- After all decisions are final, the monitor will randomly pick one of the 8 decision situations for computing earnings. The draw will be made by picking a card out of a shuffled deck of cards numbered from 1 to 8 . The drawing will be made in public, at the front of the room.

- Groups of 4 persons have been randomly created based on participant numbers.

- Your cash earnings will depend on your decisions and the decisions of the other three participants with whom you are grouped.

- Your decisions and earnings are your private information. These decisions will be recorded only by your participant number and not your name. You will be informed of the decisions of the other participants for your group only for the decision situation chosen for computing earnings. However, you will not know the identities (names or numbers) of the participants who made those decisions.

- All decision situations are described in Experimental Currency Units (ECUs). At the end of the experiment you will be paid in cash at a rate of 600 pesos for every ECU you earn.

- In addition to your earnings from the experiment, you will receive a "show-up" payment equal to 5000 pesos.

- You are free to leave at any point during the experiment, however if you decide to leave before the end of the experiment you will not be paid.

- If you agree to participate you will need to sign a consent form. 
- At the end of the experiment, while we are calculating your earnings, you will be asked to complete a short questionnaire.

- The experiment will last approximately 2 hours.

$$
\text { You are participant ___ for all decision situations. }
$$

\section{DECISION SITUATION 1}

In today's experiment, you will have an Individual Fund and your group of four will have a Group Fund.

STARTING BALANCES: Each group of four begins with 100 tokens placed in their initial Group Fund. Each token in the initial Group Fund is worth 2 ECUs. Thus, each group begins with an initial Group Fund worth 200 ECUs. Each person begins with 0 tokens placed in his/her initial Individual Fund.

DECISION TASK: Each person will decide privately whether or not to move tokens from the initial Group Fund to his/her own Individual Fund.

Each person can move up to a maximum of 25 tokens from the initial Group Fund to his/her own Individual Fund. Each token that a person moves from the initial Group Fund increases the value of his/her own Individual Fund by 1 ECU. However, each token moved from the initial Group Fund reduces the value of the final Group Fund by 2 ECUs for his/her group. That is, the value of the final Group Fund is the result of subtracting from the initial Group Fund the sum of tokens removed by each participant in your group. Each person's decision must be in whole tokens $(0,1,2,3,4,5, \ldots, 20,21,22,23,24$ or 25$)$.

EARNINGS: In each group of four, an individual's earnings will be the sum of the value of that person's Individual Fund plus a fourth $(1 / 4)$ of the value of the final Group Fund; meaning each subject gets a return of 0.5 ECUs from each token in the final Group Fund.

Three examples to illustrate individual earnings:

- If a person moves 0 tokens from the initial Group Fund, that increases the value of his/her own Individual Fund by 0 ECUs and reduces the resulting value of the final Group Fund by 0 ECUs ( 0 tokens moved x 2 ECUs per token moved).

- If a person moves 10 tokens from the initial Group Fund, that increases the value of his/her own Individual Fund by 10 ECUs and reduces the resulting value of the final Group Fund by 20 ECUs (10 tokens moved x 2 ECUs per token moved).

- If a person moves 25 tokens from the initial Group Fund, that increases the value of his/her own Individual Fund by 25 ECUs and reduces the resulting value of the final Group Fund by 50 ECUs (25 tokens moved x 2 ECUs per token moved).

Three additional examples to illustrate group earnings:

- If a group moves 0 tokens from the initial Group Fund, that yields a final Group Fund with a value of 200 ECUs (200 ECUs minus 0 tokens moved x 2 ECUs per token moved). 
- If a group moves 50 tokens from the initial Group Fund, that yields a final Group Fund with a value of 100 ECUs (200 ECUs minus 50 tokens moved x 2 ECUs per token moved).

- If a group moves 100 tokens from the initial Group Fund, that yields a final Group Fund with a value of 0 ECUs (200 ECUs minus 100 tokens moved x 2 ECUs per token moved).

Quiz 1:

1.1. In Decision Situation 1, the starting value of your Individual Fund is ECUs.

1.2. In Decision Situation 1, the starting value of the initial Group Fund is

ECUs.

1.3. In Decision Situation 1, each token you move from the initial Group Fund increases the value of your Individual Fund by ECUs and reduces the value of the final Group Fund by ECUs.

\section{DECISION SITUATION 2}

Decision Situation 2 is the same as Decision Situation 1, except for the following change: Each token that a person moves from the initial Group Fund increases the value of his/her own Individual Fund by 1.4 ECU. Quiz 2:

2.1. In Decision Situation 2, the starting value of your Individual Fund is ECUs.

2.2. In Decision Situation 2, the starting value of the initial Group Fund is ECUs.

2.3. In Decision Situation 2, each token you move from the initial Group Fund increases the value of your Individual Fund by ECUs and reduces the value of the final Group Fund by ECUs.

\section{DECISION SITUATION 3}

Decision Situation 3 is the same as Decision Situation 1, except for the following change: Each token that a person moves from the initial Group Fund increases the value of his/her own Individual Fund by 0.6 ECU. Quiz 3:

3.1. In Decision Situation 3, the starting value of your Individual Fund is ECUs.

3.2. In Decision Situation 3, the starting value of the initial Group Fund is ECUs.

3.3. In Decision Situation 3, each token you move from the initial Group Fund increases the value of your Individual Fund by ECUs and reduces the value of the final Group Fund by ECUs.

\section{DECISION SITUATION 4}

Decision Situation 4 is the same as Decision Situation 1, except for the following change: Each token that a person moves from the initial Group Fund increases the value of his/her own Individual Fund. For two members of each group, tokens moved to the Individual Fund have a value of 0.6 ECUs. For the other two members of each group, tokens moved to the Individual Fund have a value of 1.4 ECUs.

You will receive ECUs for each token you move to your Individual Fund.

Quiz 4:

4.1. In Decision Situation 4, the starting value of your Individual Fund is ECUs.

4.2. In Decision Situation 4, the starting value of the initial Group Fund is ECUs. 
4.3. In Decision Situation 4, group members have different values for tokens moved to their Individual Fund.

For you and one other group member the value is ECUs. For the other two group members the value is ECUs.

4.4. In Decision Situation 4, each token you move from the initial Group Fund increases the value of your Individual Fund by ECUs and reduces the value of the final Group Fund by ECUs.

\section{DECISION SITUATION 5}

Decision Situation 5 is the same as Decision Situation 1, except for the following change:

For each token removed from the initial Group Fund by a member of your four person group there is a $1 \%$ chance that the value of the final Group Fund is reduced by one-half.

Two examples:

- If 20 tokens were removed from the initial Group Fund, this would mean there is a $20 \%$ chance that the value of the final Group Fund will be 80 ECUs ( $1 / 2$ of 200 ECUs minus 20 tokens removed x 2 ECUs per token moved) and a 80\% chance that the value of the final Group Fund remains at 160 ECUs (200 ECUs minus 20 tokens removed x 2 ECUs per token moved).

- If 60 tokens were removed from the initial Group Fund, this would mean there is a $60 \%$ chance that the value of the final Group Fund will be 40 ( $1 / 2$ of 200 ECUs minus 60 tokens removed x 2 ECUs per token moved) and a $40 \%$ chance that the value of the final Group Fund remains at 80 ECUs (200 ECUs minus 60 tokens removed x 2 ECUs per token moved).

Otherwise, all other aspects are the same as in Decision Situation 1. Thus, each token that you remove from the initial Group Fund increases the value of your Individual Fund by 1 ECU and reduces the value of the Group Fund by 2 ECUs.

After all decisions are made, if Decision 5 is randomly drawn for determining cash earnings, the following procedure will be followed.

- A deck of cards numbered 1-100 will be displayed and shuffled. One card will be drawn from the deck of cards by the monitor. The drawing will be made in public, at the front of the room.

- For each group of four, if the card drawn is less than or equal to the number of tokens removed from the initial Group Fund, the value of the final Group Fund will be reduced by half $(1 / 2)$ of its ending value. If the card drawn is greater than the number of tokens removed from the initial Group Fund, then the value of the final Group Fund will not be reduced.

EARNINGS: In each group of four, an individual's earnings will be the sum of the value of that person's Individual Fund plus a fourth (1/4) of the value of the final Group Fund for his/her group; meaning each subject gets a return of 0.5 ECUs from each token in the final Group Fund.

Three examples to illustrate group earnings:

- If a group moves 0 tokens from the initial Group Fund, that yields a final Group Fund of value 200 ECUs. In this case we will not draw a card from the deck of cards. The value of the final Group Fund will remain at 200 ECUs. 
- If a group moves 60 tokens from the initial Group Fund, that yields a final Group Fund with a value of 80 ECUs (200 ECUs minus 60 tokens moved x 2 ECUs per token moved). In this case, we will draw one card from the deck of cards. If the card drawn is less than or equal to 60 (number of tokens removed), the value of the final Group Fund will be reduced to 40 ECUs ( $1 / 2$ of its ending value, $(1 / 2$ of 80 ECUs). If the card drawn is greater than 60, then the value of the final Group Fund will remain at 80 ECUs.

- If a group moves 100 tokens from the initial Group Fund, that yields a final Group Fund with a value of 0 ECUs (200 ECUs minus 100 tokens moved x 2 ECUs per token moved). In this case, we will not draw a card from the deck of cards. The value of the final Group Fund will remain at 0 ECUs.

Quiz 5:

5.1. In Decision Situation 5 the starting value of your Individual Fund is ECUs.

5.2. In Decision Situation 5, the starting value of the initial Group Fund is

ECUs.

5.3. In Decision Situation 5, each token you move from the initial Group Fund increases the value of your Individual Fund by ECUs and reduces the value of the final Group Fund by ECUs. In addition, each token a group member removes from the initial Group Fund increases the chances that the final Group Fund will lose $1 / 2$ of its value by $\%$.

\section{DECISION SITUATION 6}

Decision Situation 6 is the same as Decision Situation 5, except for the following change: Each token that a person moves from the initial Group Fund increases the value of his/her own Individual Fund by 1.4 ECUs.

Remember: For each token removed from the initial Group Fund by a member of your four person group there is a $1 \%$ chance that the value of the final Group Fund is reduced by one-half.

Quiz 6:

6.1 In Decision Situation 6, the starting value of your Individual Fund is ECUs.

6.2. In Decision Situation 6, the starting value of the initial Group Fund is ECUs.

6.3. In Decision Situation 6, each token you move from the initial Group Fund increases the value of your Individual Fund by ECUs and reduces the value of the final Group Fund by ECUs. In addition, each token a group member removes from the initial Group Fund increases the chances that the final Group Fund will lose $1 / 2$ of its value by $\%$.

\section{DECISION SITUATION 7}

Decision Situation 7 is the same as Decision Situation 5, except for the following change: Each token that a person moves from the initial Group Fund increases the value of his/her own Individual Fund by 0.6 ECUs.

Remember: For each token removed from the initial Group Fund by a member of your four person group there is a $1 \%$ chance that the value of the final Group Fund is reduced by one-half.

Quiz 7:

7.1 In Decision Situation 7, the starting value of your Individual Fund is ECUs.

7.2. In Decision Situation 7, the starting value of the initial Group Fund is ECUs. 
7.3. In Decision Situation 7, each token you move from the initial Group Fund increases the value of your Individual Fund by ECUs and reduces the value of the final Group Fund by ECUs. In addition, each token a group member removes from the initial Group Fund increases the chances that the final Group

Fund will lose $1 / 2$ of its value by $\%$.

\section{DECISION SITUATION 8}

Decision Situation 8 is the same as Decision Situation 5, except for the following change: Each token that a person moves from the initial Group Fund increases the value of his/her own Individual Fund. For two members of each group, tokens moved to the Individual Fund have a value of 0.6 ECUs. For the other two members of each group, tokens moved to the Individual Fund have a value of 1.4 ECUs.

You will receive ___ ECUs for each token you move to your Individual Fund.

Remember: For each token removed from the initial Group Fund by a member of four person group there is a $1 \%$ chance that the value of the final Group Fund is reduced by one-half.

Quiz 8:

8.1. In Decision Situation 8, the starting value of your Individual Fund is ECUs.

8.2. In Decision Situation 8, the starting value of the Group Fund is ECUs.

8.3. In Decision Situation 8, group members have different values for tokens moved to their Individual Fund. For you and one other group member the value is ECUs. For the other two group members the value is ECUs.

8.4. In Decision Situation 8, each token you move from the initial Group Fund increases the value of your Individual Fund by ECUs and reduces the value of the final Group Fund by ECUs. In addition, each token a group member removes from the initial Group Fund increases the chances that the final Group Fund will lose $1 / 2$ of its value by $\%$. 


\section{Decision Sheet: Participant number}

For each decision situation: Write in the number of tokens you wish to move from the initial Group Fund to your individual Fund.

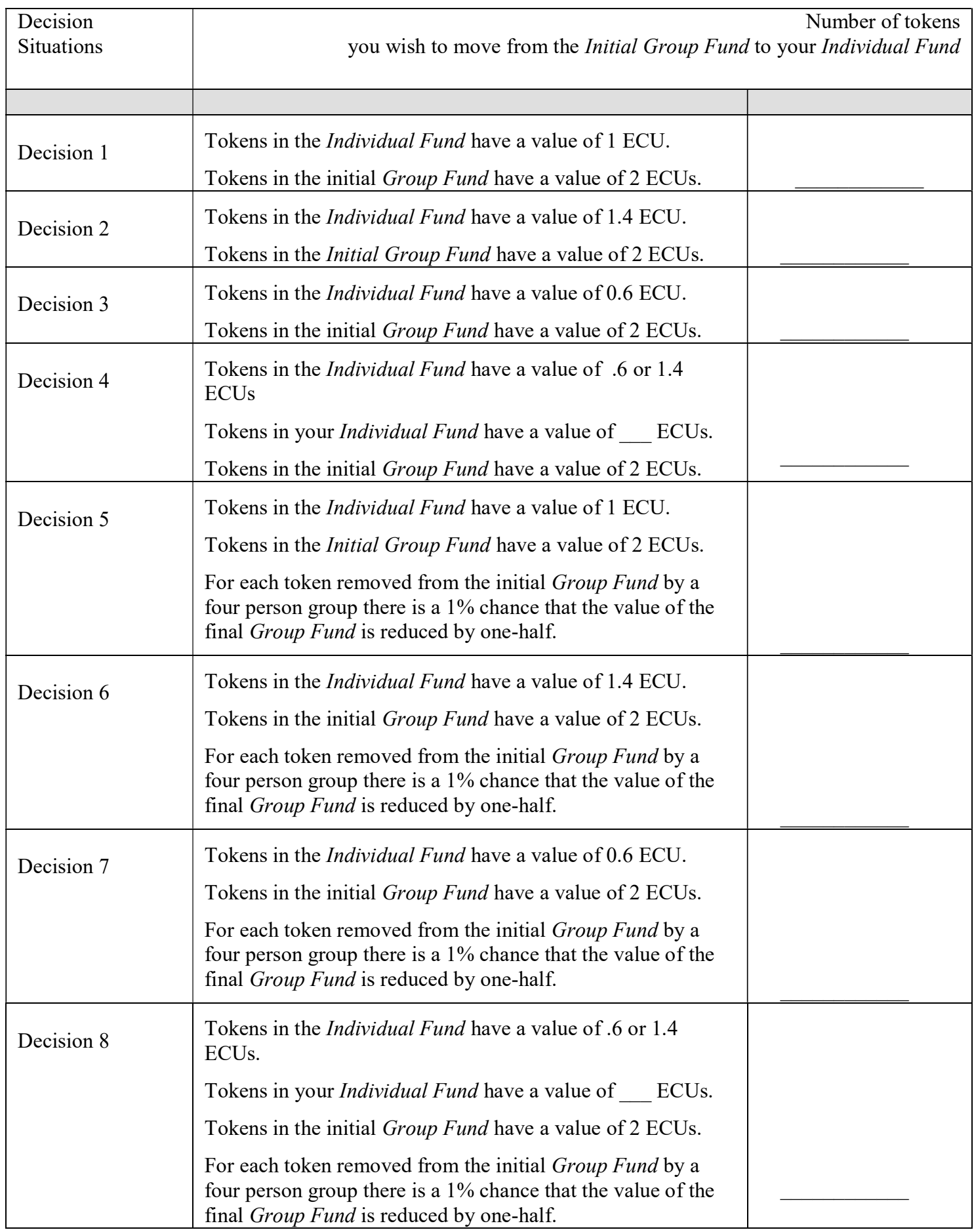


BONUS QUESTION

In this section, you will be asked to forecast (for each decision setting) the per person average number of tokens (not including your decision) moved from the Group Fund to the Individual Fund (a number between 0 and 25). If you want, your forecast may include up to two decimals. In addition to your earnings from one of the 8 decision making situations, we will pay you an extra bonus depending on how close your forecast is to the actual average number of tokens moved to the Individual Fund by members of your group.

Your bonus earnings will be determined in the following way: If your forecast of the per person average number of tokens moved from the Group Fund to the Individual Fund (for the chosen decision situation) is equal to or not more than 1 token away from the actual average, you will earn an additional 8,000 pesos. If your forecast is more than 1 token away from the average you will earn 3,000 pesos divided by the (absolute) distance between your forecast and the actual average moved from the Group Fund.

\begin{tabular}{|c|c|c|}
\hline $\begin{array}{l}\text { Decision } \\
\text { Situations }\end{array}$ & \multicolumn{2}{|c|}{$\begin{array}{l}\text { Per person average number of tokens moved by the other } 3 \text { members of your group from the } \\
\text { Group Fund to the Individual Fund (a number between } 0 \text { and 25) }\end{array}$} \\
\hline Decision 1 & $\begin{array}{l}\text { Per Person Average number of tokens moved in your group from the Group } \\
\text { Fund to the Individual Fund (not including your decision) }\end{array}$ & \\
\hline Decision2 & $\begin{array}{l}\text { Per Person Average number of tokens moved in your group from the Group } \\
\text { Fund to the Individual Fund (not including your decision) }\end{array}$ & \\
\hline Decision 3 & $\begin{array}{l}\text { Per Person Average number of tokens moved in your group from the Group } \\
\text { Fund to the Individual Fund (not including your decision) }\end{array}$ & \\
\hline Decision 4 & $\begin{array}{l}\text { a) Per Person Average number of tokens moved from the Group Fund to the } \\
\text { Individual Fund (not including your decision) by members of your group } \\
\text { having an Individual Fund value of } 0.6 \text { UME } \\
\text { b) Per Person Average number of tokens moved from the Group Fund to the } \\
\text { Individual Fund (not including your decision) by members of your group } \\
\text { having an Individual Fund value of } 1.4 \mathrm{UME}\end{array}$ & \\
\hline Decision 5 & $\begin{array}{l}\text { Per Person Average number of tokens moved in your group from the Group } \\
\text { Fund to the Individual Fund (not including your decision) }\end{array}$ & \\
\hline Decision 6 & $\begin{array}{l}\text { Per Person Average number of tokens moved in your group from the Group } \\
\text { Fund to the Individual Fund (not including your decision) }\end{array}$ & \\
\hline Decision 7 & $\begin{array}{l}\text { Per Person Average number of tokens moved in your group from the Group } \\
\text { Fund to the Individual Fund (not including your decision) }\end{array}$ & \\
\hline Decision 8 & $\begin{array}{l}\text { a) Per Person Average number of tokens moved from the Group Fund to the } \\
\text { Individual Fund (not including your decision) by members of your group } \\
\text { having an Individual Fund value of } 0.6 \mathrm{UME} \\
\text { b) Per Person Average number of tokens moved from the Group Fund to the } \\
\text { Individual Fund (not including your decision) by members of your group } \\
\text { having an Individual Fund value of } 1.4 \mathrm{UME}\end{array}$ & \\
\hline
\end{tabular}


University of Innsbruck - Working Papers in Economics and Statistics Recent Papers can be accessed on the following webpage:

http://eeecon.uibk.ac.at/wopec/

2012-25 Esther Blanco, Maria Claudia Lopez, James M. Walker: Appropriation in the commons: variations in the opportunity costs of conservation

2012-24 Edgar C. Merkle, Jinyan Fan, Achim Zeileis: Testing for measurement invariance with respect to an ordinal variable

2012-23 Lukas Schrott, Martin GÃchter, Engelbert Theurl: Regional development in advanced countries: A within-country application of the Human Development Index for Austria

2012-22 Glenn Dutcher, Krista Jabs Saral: Does team telecommuting affect productivity? An experiment

2012-21 Thomas Windberger, Jesus Crespo Cuaresma, Janette Walde: Dirty floating and monetary independence in Central and Eastern Europe - The role of structural breaks

2012-20 Martin Wagner, Achim Zeileis: Heterogeneity of regional growth in the European Union

2012-19 Natalia Montinari, Antonio Nicolo, Regine Oexl: Mediocrity and induced reciprocity

2012-18 Esther Blanco, Javier Lozano: Evolutionary success and failure of wildlife conservancy programs

2012-17 Ronald Peeters, Marc Vorsatz, Markus Walzl: Beliefs and truth-telling: A laboratory experiment

2012-16 Alexander Sebald, Markus Walzl: Optimal contracts based on subjective evaluations and reciprocity

2012-15 Alexander Sebald, Markus Walzl: Subjective performance evaluations and reciprocity in principal-agent relations

2012-14 Elisabeth Christen: Time zones matter: The impact of distance and time zones on services trade

2012-13 Elisabeth Christen, Joseph Francois, Bernard Hoekman: CGE modeling of market access in services 
2012-12 Loukas Balafoutas, Nikos Nikiforakis: Norm enforcement in the city: A natural field experiment forthcoming in European Economic Review

2012-11 Dominik Erharter: Credence goods markets, distributional preferences and the role of institutions

2012-10 Nikolaus Umlauf, Daniel Adler, Thomas Kneib, Stefan Lang, Achim Zeileis: Structured additive regression models: An R interface to Bayes X

2012-09 Achim Zeileis, Christoph Leitner, Kurt Hornik: History repeating: Spain beats Germany in the EURO 2012 Final

2012-08 Loukas Balafoutas, Glenn Dutcher, Florian Lindner, Dmitry Ryvkin: To reward the best or to punish the worst? A comparison of two tournament mechanisms with heterogeneous agents

2012-07 Stefan Lang, Nikolaus Umlauf, Peter Wechselberger, Kenneth Harttgen, Thomas Kneib: Multilevel structured additive regression

2012-06 Elisabeth Waldmann, Thomas Kneib, Yu Ryan Yu, Stefan Lang: Bayesian semiparametric additive quantile regression

2012-05 Eric Mayer, Sebastian Rueth, Johann Scharler: Government debt, inflation dynamics and the transmission of fiscal policy shocks

2012-04 Markus Leibrecht, Johann Scharler: Government size and business cycle volatility; How important are credit constraints?

2012-03 Uwe Dulleck, David Johnston, Rudolf Kerschbamer, Matthias Sutter: The good, the bad and the naive: Do fair prices signal good types or do they induce good behaviour?

2012-02 Martin G. Kocher, Wolfgang J. Luhan, Matthias Sutter: Testing a forgotten aspect of Akerlofât ${ }^{\mathrm{TM}} \mathrm{S}$ gift exchange hypothesis: Relational contracts with individual and uniform wages

2012-01 Loukas Balafoutas, Florian Lindner, Matthias Sutter: Sabotage in tour- naments: Evidence from a natural experiment forthcoming in Kyklos

2011-29 Glenn Dutcher: How Does the Social Distance Between an Employee and a Manager affect Employee Competition for a Reward?

2011-28 Ronald Peeters, Marc Vorsatz, Markus Walzl: Truth, trust, and sanctions: On institutional selection in sender-receiver games published in Scandinavian Journal of Economics

2011-27 Haoran He, Peter Martinsson, Matthias Sutter: Group Decision Making Under Risk: An Experiment with Student Couples forthcoming in Economics Letters 
2011-26 Andreas Exenberger, Andreas Pondorfer: Rain, temperature and agricultural production: The impact of climate change in Sub-Sahara Africa, 19612009

2011-25 Nikolaus Umlauf, Georg Mayr, Jakob Messner, Achim Zeileis: WhyDoes It Always Rain on Me? A Spatio-Temporal Analysis of Precipitation in Austria forthcoming in Austrian Journal of Statistics

2011-24 Matthias Bank, Alexander Kupfer, Rupert Sendlhofer: Performancesensitive government bonds - A new proposal for sustainable sovereign debtmanagement

2011-23 Gerhard Reitschuler, Rupert Sendlhofer: Fiscal policy, trigger points and interest rates: Additional evidence from the U.S.

2011-22 Bettina Grün, Ioannis Kosmidis, Achim Zeileis: Extended beta regression in R: Shaken, stirred, mixed, and partitioned published in Journal of Statistical Software

2011-21 Hannah Frick, Carolin Strobl, Friedrich Leisch, Achim Zeileis: Flexible Rasch mixture models with package psychomix published in Journal of Statistical Software

2011-20 Thomas Grubinger, Achim Zeileis, Karl-Peter Pfeiffer: evtree: Evolutionary learning of globally optimal classification and regression trees in $\mathrm{R}$

2011-19 Wolfgang Rinnergschwentner, Gottfried Tappeiner, Janette Walde: Multivariate stochastic volatility via wishart processes - A continuation

2011-18 Jan Verbesselt, Achim Zeileis, Martin Herold: Near Real-Time Disturbance Detection in Terrestrial Ecosystems Using Satellite Image Time Series: Drought Detection in Somalia forthcoming in Remote Sensing and Environment

2011-17 Stefan Borsky, Andrea Leiter, Michael Pfaffermayr: Does going greenpay off? The effect of an international environmental agreement on tropicaltimber trade

2011-16 Pavlo Blavatskyy: Stronger Utility

2011-15 Anita Gantner, Wolfgang Höchtl, Rupert Sausgruber: The pivotal me-chanism revisited: Some evidence on group manipulationrevised version withauthors Francesco Feri, Anita Gantner, Wolfgang H İ`ochtl and Rupert Sausgru-ber forthcoming inExperimentalEconomics

2011-14 David J. Cooper, Matthias Sutter: Role selection and team performance

2011-13 Wolfgang Höchtl, Rupert Sausgruber, Jean-Robert Tyran: Inequalityaversion and voting on redistribution 
2011-12 Thomas Windberger, Achim Zeileis: Structural breaks in inflation dynamics within the European Monetary Union

2011-11 Loukas Balafoutas, Adrian Beck, Rudolf Kerschbamer, Matthias Sutter: What drives taxi drivers? A field experiment on fraud in a market forcredence goods

2011-10 Stefan Borsky, Paul A. Raschky: A spatial econometric analysis of compliance with an international environmental agreement on open access resources

2011-09 Edgar C. Merkle, Achim Zeileis: Generalized measurement in variance tests with application to factor analysis forthcoming in Psychometrika

2011-08 Michael Kirchler, Jürgen Huber, Thomas Stöckl: Thar she bursts reducing confusion reduces bubbles published in American Economic Review

2011-07 Ernst Fehr, Daniela Rützler, Matthias Sutter: :The development of egalitarianism, altruism, spite and parochialism in childhood and adolescence

2011-06 Octavio Fern İandez-Amador, Martin Gächter, Martin Larch, GeorgPeter: Monetary policy and its impact on stock market liquidity: Evidencefrom the euro zone

2011-05 Martin Gächter, Peter Schwazer, Engelbert Theurl: Entry and exit of physicians in a two-tiered public/private health care system

2011-04 Loukas Balafoutas, Rudolf Kerschbamer, Matthias Sutter: Distributional preferences and competitive behavior published in Journal of Economic Behavior and Organization

2011-03 Francesco Feri, Alessandro Innocenti, Paolo Pin: Psychological pressurein competitive environments: Evidence from a randomized natural experiment:Comment

2011-02 Christian Kleiber, Achim Zeileis: Reproducible Econometric Simulations forthcoming in Journal of Econometric Methods

2011-01 Carolin Strobl, Julia Kopf, Achim Zeileis: A new method for detectingdifferential item functioning in the Rasch model 


\title{
University of Innsbruck
}

\section{Working Papers in Economics and Statistics}

$2012-25$

Esther Blanco, Maria-Claudia Lopez, James M. Walker

The opportunity costs of conservation with deterministic and probabilistic degradation externalities

\begin{abstract}
This experimental study examines variations in the opportunity cost of conservation(the foregone private earnings from appropriation) in two linear appropriation gamesthat include symmetric and asymmetric subject payoffs. In the first game, appropria-tion leads to deterministic degradation in the value of the commons. In the secondgame, appropriation leads to both deterministic and probabilistic catastrophic de-gradation, introducing endogenous uncertainty in the value of the opportunity costof conserving the commons. The experimental design abstracts away from path-dependent group dynamics that allow for reputation building. Instead the design isbuilt around a one-shot, within subject, decision setting in which there is no poten-tial to observe others decisions or signal oneâ ${ }^{\mathrm{TM}_{\mathrm{S}}}$ own intentions. In summary, subjectssystematically decrease appropriation the lower the opportunity cost of conserva-tion, and in decision settings with asymmetric game parameters, subjects appearto react primarily to their own marginal incentives rather than others. Moreover,the addition of probabilistic degradation leads to further decreases in appropriati-on. These decreases, however, are not large enough to offset decreases in expectedefficiency due to expected losses in the value of the commons.
\end{abstract}

ISSN 1993-4378 (Print)

ISSN 1993-6885 (Online) 